\title{
Proregenerative Microenvironment Triggered by Donor Mesenchymal Stem Cells Preserves Renal Function and Structure in Mice with Severe Diabetes Mellitus
}

\author{
Fernando Ezquer, ${ }^{1}$ Maximiliano Giraud-Billoud, ${ }^{1,2}$ Daniel Carpio, ${ }^{3}$ Fabián Cabezas, ${ }^{1,4}$ \\ Paulette Conget, ${ }^{1}$ and Marcelo Ezquer ${ }^{1}$ \\ ${ }^{1}$ Centro de Medicina Regenerativa, Facultad de Medicina Clínica Alemana, Universidad del Desarrollo, Avenida Las Condes 12438 , \\ Santiago, Chile \\ ${ }^{2}$ Laboratorio de Fisiología (IHEM-CONICET) and Instituto de Fisiología, Facultad de Ciencias Médicas, \\ Universidad Nacional de Cuyo, Casilla de Correo 33, Mendoza, Argentina \\ ${ }^{3}$ Instituto de Anatomía, Histología y Patología, Facultad de Medicina Universidad Austral de Chile, Isla Teja s/n, Valdivia, Chile \\ ${ }^{4}$ Facultad de Ciencias Biológicas, Universidad Andrés Bello, Avenida Los Leones 745, Santiago, Chile
}

Correspondence should be addressed to Marcelo Ezquer; mezquer@udd.cl

Received 2 March 2015; Revised 30 April 2015; Accepted 14 May 2015

Academic Editor: Florian Toegel

Copyright (c) 2015 Fernando Ezquer et al. This is an open access article distributed under the Creative Commons Attribution License, which permits unrestricted use, distribution, and reproduction in any medium, provided the original work is properly cited.

\begin{abstract}
The aim of our work was to evaluate, in an animal model of severe diabetes mellitus, the effect of mesenchymal stem cells (MSCs) administration on diabetic nephropathy (DN) progression. After diabetes induction, one group of mice received the vehicle $(\mathrm{DM})$ and other group received a single dose of MSCs (DM + MSCs). DM + MSCs mice showed a significant improvement in functional parameters of the kidney compared with untreated mice. While DM mice presented marked histopathological changes characteristics of advanced stages of DN (fibrosis, glomerulosclerosis, glomerular basement membrane thickening, capillary occlusion, decreased podocyte density, and effacement of foot processes), DM + MSCs mice showed only slight tubular dilatation. The renoprotection was not associated with an improvement in diabetic condition and very low number of donor cells was found in the kidney of DM + MSCs mice, suggesting that renoprotection could be mediated by paracrine effects. Indeed, DM + MSC mice presented increased renal proliferation index, decreased renal apoptotic index and the restoration of proregenerative factors, and anti-inflammatory cytokines levels. Moreover, macrophage infiltration and oxidative stress damage were also reduced in DM + MSCs mice. Our data demonstrate that MSC administration triggers a proregenerative microenvironment in DN kidney, which allows the preservation of the renal function even if diabetes was uncorrected.
\end{abstract}

\section{Introduction}

Diabetic nephropathy (DN) is the major microvascular complication in diabetic patients and it remains the leading cause of chronic kidney disease, responsible for approximately $50 \%$ of all cases of end-stage renal disease worldwide [1]. The development of DN is stimulated by sustained hyperglycaemia [2], and its key pathologic features include gradual thickening of the glomerular basement membrane (GBM) and glomerular hypertrophy accompanied by mesangial matrix expansion with accumulation of several matrix proteins, such as collagen type I, laminin $\beta 1$, and fibronectin [2].
These molecules contribute to the reduction in the glomerular filtration surface area and to an increase in tubular interstitial fibrosis and glomerulosclerosis. Clinically, there is a decline in glomerular filtration rate with progressive increase in urinary albumin excretion that ultimately leads to end-stage renal failure [3].

Hyperglycaemia induces cellular changes in various cell types present in the kidney. In the normal glomerulus, the podocytes (glomerular epithelial cells) have an arborized phenotype, and its terminal branches or foot processes cover the outer wall of the glomerular capillaries. During proteinuric stages, the podocyte typical morphology is lost 
and is converted into a flatter epithelial cell, a process named as "foot process effacement." In this process, the cytoskeleton that normally supports the delicate architecture of the foot processes is condensed at the basal side of the flattened podocytes, altering its functionality [4]. Therefore, podocyte injury is associated with the development of albuminuria and the appearance of more severe glomerular structural abnormalities [4].

Throughout diabetes onset, high levels of blood glucose induce both oxidative stress and inflammation, which are intimately linked with the development of DN [5-7]. Oxidative stress is caused by an imbalance between the production of reactive oxygen species (ROS) and the biological system's ability to readily detoxify the reactive intermediates or repair the resulting damage. When this occurs, oxidation of essential macromolecules including proteins, lipids, carbohydrates, and DNA is produced, leading to the apoptosis of damaged cells [6].

Higher ROS levels can also induce the production of inflammatory cytokines, which stimulate the production of free radicals exacerbating DN progression [5]. Therefore, intensive glycemic control is the main intervention to reduce oxidative stress.

Transforming growth factor beta (TGF- $\beta$ ) is a multifunctional cytokine that plays a critical role in the pathogenesis of DN by stimulation of the synthesis of extracellular matrix molecules including collagen type I, fibronectin and laminin $\beta 1$, leading to renal fibrosis [8].

Stem cell therapy has been envisioned as a novel strategy for various diseases since it has the potential to be more effective than single-agent drug therapies [9]. Multipotent mesenchymal stromal cells, also referred as mesenchymal stem cells (MSCs), are a population of self-renewable and undifferentiated cells present in the bone marrow and other mesenchymal tissues of adult individuals [10]. MSCs are attractive candidates for renal repair, since nephrons are of mesenchymal origin and because stromal cells are of crucial importance for signalling, leading to differentiation of both nephrons and collecting ducts [11].

Several studies have shown that the administration of MSCs leads to the amelioration of acute and chronic kidney injury [12]. In those reports, immune modulation and antiapoptotic effects have been associated with the therapeutic effect, suggesting that MSCs can act through paracrine mechanisms $[13,14]$. Additionally, MSC-based therapies have been considered to be promising strategies to treat patients with diabetes mellitus and its main complications [15]. We and others have demonstrated that the systemic administration of MSCs into immunologically induced type 1 diabetic mice reduced microalbuminuria and preserved normal renal histology [16-20]. However, animal models used only developed the earlier harbingers of DN; furthermore in these studies, it is difficult to distinguish whether restoration of kidney function is based on direct effect of transplanted cells on renal tissue or indirectly, through improvement of pancreatic endocrine function. To answer this question and taking into account that hyperglycaemia is the driving force for the development of DN, previously, we used a severe diabetic animal model induced by the administration of a single high dose $(200 \mathrm{mg} / \mathrm{kg})$ of streptozotocin (STZ) in C57BL/6 mice [21]. This protocol generates an irreversible and massive destruction of insulin-producing cells and severe hyperglycaemia, leading to a rapid progression of renal failure and the appearance of most of the characteristics DN pathognomonic signs [21-23]. In this model, multiple systemic administrations of MSCs did not reverse hyperglycaemia but protect kidneys from progression to macroalbuminuria and prevent the development of marked histological alterations [21].

The aim of the present work is to further characterize the therapeutic effect of MSC administration in an animal model of severe diabetes mellitus, particularly regarding renal failure.

For this purpose, eight weeks after the massive cytotoxic destruction of insulin-producing cells, severe diabetic mice were separated into two groups: one received the vehicle (DM mice) and the other $0.5 \times 10^{6}$ MSCs (DM + MSCs mice). Two and eight weeks later, the function, histopathology, ultrastructure, cell proliferation, protein profile, gene expression, oxidative stress, and inflammation of kidneys were examined. Donor MSCs biodistribution was also assessed.

\section{Material and Methods}

2.1. Animals. C57BL/6 and C57BL/6-Tg (ACTB-EGFP) $1 \mathrm{Osb} / \mathrm{J}$ mice (Jackson Laboratory) were housed at constant temperature and humidity, with a $12: 12 \mathrm{~h}$ light-dark cycle and unrestricted access to a standard diet and water. When required, animals were slightly anaesthetized with sevoflurane (Abbott) or ketamine (Drag Pharma) plus xylazine (Centrovet). All procedures were in accordance with institutional and international standards for the human care and use of laboratory animals [Ethic Committee of Facultad de Medicina Clinica Alemana, Universidad del Desarrollo and Animal Welfare Assurance Publications A54427-01, Office for Protection from Research Risks, Division of Animal Welfare, NIH (National Institute of Health), Bethesda, MD, USA].

2.2. Severe Diabetes Induction. Eight-week-old male C57BL/ 6 mice were slightly anesthetized and received intraperitoneally $200 \mathrm{mg} / \mathrm{kg} \mathrm{STZ} \mathrm{(Calbiochem)} \mathrm{immediately} \mathrm{after} \mathrm{dis-}$ solving in $0.1 \mathrm{M}$ citrate buffer at $\mathrm{pH} 4.5$ (DM mice) or citrate buffer only (Normal mice). This protocol of STZ administration causes massive cytotoxic destruction of insulinproducing cells, generating a severe hyperglycemic condition, which accelerates the appearance of the complications associated to diabetes, particularly DN [21-23].

2.3. MSC Isolation and Ex Vivo Expansion. Eight- to 10-weekold male C57BL/6 or C57BL/6-Tg (ACTB-EGFP) 1Osb/J mice were sacrificed by cervical dislocation. Bone marrow cells were obtained by flushing femurs and tibias with sterile phosphate-buffered saline (PBS). After centrifugation, cells were resuspended in $\alpha$-minimum essential medium ( $\alpha$ MEM) (Gibco) supplemented with 10\% selected fetal bovine serum (Gibco) and $0.16 \mathrm{mg} / \mathrm{mL}$ gentamicin (Sanderson Laboratory) and plated at a density of $1 \times 10^{6}$ nucleated cells $/ \mathrm{cm}^{2}$. 
Nonadherent cells were removed after $72 \mathrm{~h}$ by media change. When foci reached confluence, adherent cells were detached with $0.25 \%$ trypsin, $2.65 \mathrm{mM}$ EDTA, centrifuged, and subcultured at 7000 cells $/ \mathrm{cm}^{2}$. After 2 subcultures, adherent cells were characterized according to their adipogenic and osteogenic differentiation potential and immunophenotypified as previously described [24, 25].

2.4. MSC Administration. Eight weeks after diabetes induction $0.5 \times 10^{6}$ MSCs or $0.5 \times 10^{6}$ MSCs $^{\text {GFP }}$ were resuspended in $0.2 \mathrm{~mL}$ of $5 \%$ mice plasma (vehicle) and administered via the tail vein to slightly anaesthetized mice (DM + MSCs mice). Untreated animals received $0.2 \mathrm{~mL}$ of vehicle (DM mice).

2.5. Sample Collection. After four hours of fasting, mice were sacrificed and blood samples were collected. Kidneys were quickly removed, decapsulated, weighted, and dissected into two parts, one of which was immediately frozen in liquid nitrogen and stored at $-80^{\circ} \mathrm{C}$ for molecular biological studies, while the other was stored in $4 \%$ paraformaldehyde for histopathological analysis.

For $24 \mathrm{~h}$ urine collection, animals were placed individually in metabolic cages for 24 hours, and urine was collected and gravimetrically measured.

2.6. Physical and Biochemical Assessment. Body weight, kidney weight, and biochemical parameters were measured eight weeks after diabetes induction (before MSC administration) and two weeks and eight weeks after MSC administration. Blood glucose levels were measured with the glucometer system Accu-Check Performa (Roche Diagnostic). Plasma insulin levels were assayed using a mouse-specific insulin ELISA kit (Ultrasensitive Mouse Insulin ELISA; Mercodia). Serum triglycerides and cholesterol levels were determined in the Architect c8000 autoanalyzer (Abbot). The renal mass index, determined by the ratio of kidney weight to body weight, was also calculated.

2.7. Renal Function Measurements. Urine samples were centrifuged to remove any suspended particle and the supernatant was used to detect albumin concentration using a mouse-specific albumin ELISA kit (Albuwell, Exocell). Urine creatinine concentration was determined by the Creatinine Companion kit (Exocell). Excretion of urinary albumin was determined using albumin to creatinine ratio.

Blood samples were centrifuged at $2000 \times \mathrm{g}$ for $10 \mathrm{~min}$, plasma creatinine levels were determined using a mousespecific enzymatic kit (Mouse Creatinine Assay, Crystal Chem) and blood urea nitrogen (BUN) using a quantitative colorimetric kit (QuantiChrom Urea Assay Kit, BioaAssay Systems).

2.8. Renal Histological and Immunofluorescence Analysis. Periodic acid Schiff (PAS) staining was performed on $4-\mu \mathrm{m}$ sections of paraffin-embedded slices. Stained slices were used to capture 50 photomicrographs (Leica DM2000 microscope and Leica DFC295 digital camera) of glomeruli containing vascular pole and/or urinary pole to determine glomerular corpuscle area, glomerular tuff area, and mesangial expansion in each image using Image-Pro Plus 4.5.1 software (Media Cybernetics). Masson's trichrome staining was used to evaluate the total area of collagen fibbers in the glomerular and in the tubulointerstitial area (20 photomicrographs each) and the leukocyte infiltrate. The fields were randomly chosen and analyzed in blind by the same specialist nephrologist. Leukocyte infiltration was graded, from 0 to 3 ; $(0=$ absent or infrequent, 1 = sporadic, scattered and ungrouped, $2=$ focalized in dense groups, and $3=$ dense foci + scattered presence) [26].

A standard point-counting method was employed to quantitate the collagen deposition $[14,27,28]$. Under high magnification of the $40 \mathrm{x}$ objective, 20 consecutive nonoverlapping fields, in each kidney, were observed. Trichromepositive points falling on glomeruli, Bowman's capsules or vessels, were excluded, while interstitial trichrome-positive points were counted for evaluation. The index of interstitial collagen volume was defined as the number of trichromepositive points in every 2000 points evaluated.

Tubular damage was graded, from 0 to 4 , according to the presence or not of dilatation, protein cylinders, atrophy, interstitial fibrosis, and leukocyte infiltration $(0=$ no changes, $1=$ changes affecting $<25 \%$ of the sample, $2=$ changes affecting $25 \%$ to $50 \%$ of the sample, 3 = changes affecting $50 \%$ to $75 \%$ of the sample, and $4=$ changes affecting $75 \%$ to $100 \%$ of the sample) [29].

Renal markers immunoreactivity was evaluated by confocal microscopy. Sections of $4 \mu \mathrm{m}$ thick were deparaffinized in Neo-Clear (Merck), rehydrated, and washed in Trisbuffered saline (TBS). Antigen retrieval was performed by incubation in $10 \mathrm{mM}$ citrate buffer $\mathrm{pH}$ 6, in a boiling water bath for $30 \mathrm{~min}$. Sections were blocked with $2 \%$ bovine serum albumin (Sigma) in TBS and incubated with the primary antibodies (WT-1 sc-192, podoplanin sc-134483 [Santa Cruz Biotechnology]; F4/80 ab74383, Ki-67 ab15589, $\alpha$-SMA ab5694 [Abcam]; GFP-D5.1XP [Cell Signaling]) in Signal Stain $\mathrm{Ab}$ diluent (Cell Signaling) at $4^{\circ} \mathrm{C}$ overnight. After washing, sections were incubated with secondary antibody (anti-rabbit IgG Fab2 Alexa Fluor555, Molecular Probes) at room temperature for $1 \mathrm{~h}$ and nuclei were counterstained with 4',6-diamino-2-fenilindol (DAPI) (BioChemica A1001, AppliChem). Sections were examined with the Fluoview FV10i confocal microscope (Olympus).

F4/80 positive cells in renal tissue were quantitatively assessed in 30 random sections per animal and expressed as F4/80 cells/cross sections [30].

In normal kidneys, $\alpha$-SMA expression is confined to the smooth muscle cells of efferent and afferent arterioles and it is never observed in glomeruli [31, 32]. Glomerulosclerosis was defined as the presence of prominent $\alpha$-SMA immunoreactivity in the mesangial area. Glomerulosclerosis index was quantified by determining the percentage of glomeruli exhibiting intense $\alpha$-SMA staining in the glomerular tuft [33]. One hundred consecutive glomeruli were examined for each animal and analyzed in blind by the same specialist nephrologist. 
Glomerular podoplanin fluorescence area was analyzed measuring the relation between podoplanin staining and glomerular tuft area [34]. Slides stained for WT-1 were used for morphometric analysis of the number of podocytes per glomerular volume. WT-1-positive nuclei per glomerular cross-section were counted and the glomerular volume per podocyte was calculated according to a previously validated method [34]. In all evaluations at least 50 glomeruli per animal were randomly selected and analyzed, and negative controls without the primary antibody were used to observe tissue background. Measurements of surface glomeruli area and the immunoreactivity analysis were made using the ImageJ 1.34 software (NIH, http://imagej.nih.gov/ij/).

2.9. Renal Ultrastructural Analysis. Small fragments of kidney tissue were fixed in $2 \%$ glutaraldehyde (Sigma), then post-fixed with $1 \%$ osmium tetroxide (Ted Pella Inc.), embedded in EMBed-812 resin (EMS, Hatfield), cut, stained, and analyzed under transmission electron microscopy (Philips Tecnai 12 Bio TWIN) at $80 \mathrm{kV}$, with standard magnifications between $\times 2,500$ and $\times 16,500$.

The electron micrographs of every animal were analyzed by setting the percentage of capillary loops with foot process effacement usually along with microvillous transformation of the podocyte and irregularities of the outer surface of the glomerular basement membrane. Then, a comparison was made between micrographs of the same magnification in the different groups of animals.

Images were analyzed in blind by a specialist pathologist.

2.10. Renal Gene Expression Analysis. Expression levels of type I collagen, TGF-betal, laminin-betal, fibronectin, nephrin, bFGF, EGF, HGF, IL-4, IL-10, and GAPDH from kidney samples were assessed by quantitative qRT-PCR. For this, total RNA was purified using TRIzol (Invitrogen) and quantified spectrophotometrically $(260 \mathrm{~nm})$. One $\mu \mathrm{g}$ of total RNA was used for reverse transcription. Real time PCR was performed in a final volume of $20 \mu \mathrm{L}$ containing $50 \mathrm{ng}$ of cDNA, PCR LightCycler-DNA Master SYBRGreen reaction mix (Roche), $3 \mathrm{mM} \mathrm{MgCl}_{2}$, and $0.5 \mu \mathrm{M}$ of each specific primer (see Supplementary Table 1 in Supplementary Material available online at http://dx.doi.org/10.1155/2015/164703), using a Light-Cycler thermocycler (Roche). To ensure that amplicons were from mRNA and do not from genomic DNA amplification, controls without reverse transcription were included. Amplicon validation was performed based on its size and melting point. Relative quantification was performed by the $\Delta \Delta \mathrm{CT}$ method. The mRNA level of each target gene was normalized against the mRNA level of GAPDH and expressed as fold of change versus Normal mice.

2.11. Quantification of Renal Mitotic and Apoptotic Indexes. Mitotic index was determined by immunohistofluorescence using an anti-Ki-67 antibody. Positive nucleus indicates cell cycle activity (G1, S, G2, or M phase). Apoptotic cells in kidney tissue slices were visualized using the DeadEnd Fluorometric TUNEL System (Promega), following the manufacturer's protocol. The nuclei were counterstained with DAPI and fluorescence was evaluated by confocal microscopy.
For the quantification of Ki-67 and TUNEL positive cells, at least 30 glomeruli and 30 tubules sections were examined for each mouse, and the number of positive stained nuclei per total cell nuclei was determined. Data were expressed as level of change versus Normal mice.

2.12. Glomerular Fluorescein Angiography. Mice were injected by tail vein with $200 \mu \mathrm{L}$ of PBS containing $10 \mathrm{mg}$ of $2 \times 10^{6}$ molecular weight fluorescein-dextran (Sigma). Five minutes later, mice were euthanized and kidneys were fixed in $4 \%$ paraformaldehyde. Four $\mu \mathrm{m}$ kidney slices were observed and photographed under confocal microscopy, and at least 50 glomeruli per animal were analyzed. The fluorescence area, representative of glomerular capillary lumen area, of each image was quantified and normalized to the glomerular tuft area [35], using the ImageJ 1.34 software, NIH.

\subsection{Assessment of Renal Oxidative Stress and Antioxidant Capacity}

2.13.1. Total Reactive Oxygen Species. Kidney slides were incubated with $10 \mu \mathrm{M}$ 2,7-dichloro-dihydro-fluorescein diacetate $\left(\mathrm{H}_{2} \mathrm{DCFDA}\right)$ (Invitrogen) in PBS containing $5 \mathrm{mM}$ Hepes for $60 \mathrm{~min}$ at $37^{\circ} \mathrm{C}$. $\mathrm{H}_{2} \mathrm{DCFDA}$ is a nonfluorescent molecule that in contact with ROS (hydrogen peroxide, peroxynitrite, and hydroxyl radicals) is rapidly converted into a highly fluorescent derivate. Kidney slides were mechanically lysed in RIPA buffer and fluorescence was measured in a fluorometer (Turner) with excitation of $450 \mathrm{~nm}$ and emission of $530 \mathrm{~nm}$. Data were presented as fluorescent units per mg of renal protein.

2.13.2. Lipid Oxidative Level. Lipid peroxidation was determined in urine samples measuring isoprostane levels. Isoprostanes are a type of eicosanoids produced nonenzymatically through the oxygen radical peroxidation of tissue phospholipids and lipoproteins. Isoprostanes appear in normal urine samples but are elevated by oxidative stress in renal tissue [36]. Urine samples were acidified to $\mathrm{pH} 3.0$ by adding $1 / 10 \mathrm{v} / \mathrm{v}$ of $1 \mathrm{~N} \mathrm{HCl}$ and further diluted in sample diluent. Level of 8-iso-prostaglandin F2 $\alpha$ was determined using the OxiSelect 8 -isoPGF $2 \alpha$ ELISA kit (Cell Biolabs, Inc.) according to the manufacturer's instructions.

2.13.3. Protein Oxidative Damage. 3-Nitrotyrosine modification of proteins is a well-established marker of protein damage by oxidative stress [37]. Kidney slides were homogenized with an extraction buffer supplemented with protease inhibitor cocktail (Thermo) and protein oxidative damage was measured with the 3-Nitrotyrosine ELISA kit (Abcam) according to the manufacturer's instructions.

2.13.4. DNA Oxidative Damage. The formation of 8-hydroxy deoxyguanosine (8-OHdG) is a ubiquitous marker of oxidative stress and its urinary excretion is associated with renal DNA oxidative damage [38]. Urinary level of 8-OHdG was evaluated by the OxiSelect Oxidative DNA Damage ELISA 
TABLE 1: MSC administration did not improve diabetic condition.

\begin{tabular}{|c|c|c|c|c|c|}
\hline & \multicolumn{2}{|c|}{ Before MSC administration } & \multicolumn{3}{|c|}{8 weeks after MSC administration } \\
\hline & Normal & $\mathrm{DM}$ & Normal & $\mathrm{DM}$ & $\mathrm{DM}+\mathrm{MSCs}$ \\
\hline Body weight (g) & $24.2 \pm 0.4$ & $20.2 \pm 0.3^{*}$ & $26.9 \pm 0.5$ & $21.4 \pm 0.5^{*}$ & $22.2 \pm 0.5^{*}$ \\
\hline Plasma insulin $(\mu \mathrm{g} / \mathrm{L})$ & $0.61 \pm 0.12$ & $0.03 \pm 0.01^{*}$ & $0.51 \pm 0.10$ & $0.07 \pm 0.03^{*}$ & $0.07 \pm 0.03^{*}$ \\
\hline Blood glucose (mg/dL) & $171 \pm 2$ & $715 \pm 49^{*}$ & $183 \pm 11$ & $766 \pm 68^{*}$ & $740 \pm 40^{*}$ \\
\hline Serum cholesterol (mg/dL) & $97 \pm 10$ & $173 \pm 20^{*}$ & $146 \pm 46$ & $291 \pm 32^{*}$ & $253 \pm 52^{*}$ \\
\hline Serum triglycerides (mg/dL) & $72 \pm 14$ & $198 \pm 35^{*}$ & $97 \pm 39$ & $337 \pm 55^{*}$ & $217 \pm 39^{*}$ \\
\hline Kidney weight (mg) & $158 \pm 4$ & $217 \pm 9^{*}$ & $177 \pm 5$ & $311 \pm 15^{*}$ & $278 \pm 14^{* \#}$ \\
\hline Kidney/body weight (mg/g) & $5.7 \pm 0.2$ & $8.9 \pm 0.3^{*}$ & $6.6 \pm 0.2$ & $15 \pm 0.7^{*}$ & $12.6 \pm 0.9^{* \#}$ \\
\hline Urine volume $(\mathrm{mL} / 24 \mathrm{~h})$ & $1.3 \pm 0.1$ & $10.0 \pm 1.6^{*}$ & $2.4 \pm 0.9$ & $16.8 \pm 2.3^{*}$ & $16.3 \pm 2.2^{*}$ \\
\hline
\end{tabular}

Physical and biochemical parameters of experimental animals. Before MSC administration (eight weeks after diabetes induction), mice received $200 \mu \mathrm{L}$ of $5 \%$ mice plasma (DM) or $0.5 \times 10^{6}$ MSCs resuspended in $200 \mu \mathrm{L}$ of $5 \%$ mice plasma (DM + MSCs) via the tail vein. All biochemical parameters were evaluated in urine and plasma samples obtained after four hours of fasting. Data are presented as mean \pm SEM, $n=12 .{ }^{*} p<0.05$ versus Normal; ${ }^{*} p<0.05$ versus DM for the same time point.

kit (Cell Biolabs, Inc) in urine samples, according to the manufacturer's instructions.

2.13.5. Total Antioxidant Capacity. Kidney slides were homogenized with an extraction buffer supplemented with protease inhibitor cocktail (Thermo). Total antioxidant capacity was measured in tissue homogenate using the Antioxidant Assay kit (Cayman Chemicals) [39] according to the manufacturer's instructions.

2.14. Quantification of Systemic Cytokines and Growth Factors. Cytokines (IL-1 $\beta$, IL-4, IL-6, IL-10, IL-13, and TNF- $\alpha$ ) and growth factors (EGF, ET1, b-FGF, HGF, and VEGF) were assessed in $25 \mu \mathrm{L}$ of plasma, using the MAGPMAG $24 \mathrm{k}$ and MCYTOMAG $70 \mathrm{k}$ assay kits (Luminex, Milliplex MAP, Millipore), respectively, according to the manufacturer's instructions. Plates were read on a Luminex 200 (Luminex Corp.) and analyzed with the Milliplex Analyst software (VigeneTech Inc.).

2.15. Statistical Analysis. Data are presented as mean \pm S.E.M. To determine the statistical significance of intergroup differences, Krustal-Wallis test was used to compare mean values among all groups, and Mann-Whitney $U$ test was used to compare mean values between two groups. $p<0.05$ was considered as statistically significant.

\section{Results}

Severe diabetes mellitus was induced in C57BL/ 6 mice by the injection of a single dose of $200 \mathrm{mg} / \mathrm{kg} \mathrm{STZ}$. This protocol causes rapid and massive destruction of insulin-producing cell. A discrete acute nephrotoxic effect has been observed after diabetes induction, with any evidence of glomerular or tubular histopathological alterations [22, 23]. Diabetic mice were maintained without insulin supplementation to allow for the progression of severe diabetes mellitus and the appearance of its complications.
Eight weeks after diabetes induction mice were hyperglycemic, polyuric, and hypoinsulinemic (Table 1). Compared to normal mice they presented reduced body weight and increased serum cholesterol, serum triglycerides, and kidney weight (Table 1). In this condition, animals were randomly assigned into two groups: one group that received the vehicle (DM mice) and another group that received a single dose of $0.5 \times 10^{6}$ bone marrow-derived MSCs (DM + MSCs mice). During the study period (16 weeks), 45\% (11/25) of DM mice and only 8\% (2/25) of DM + MSCs mice died or had to be sacrificed because of severe weight loss and cachexia. These animals were excluded from data analysis. $\mathrm{DM}$ and DM + MSCs mice remain hyperglycemic, polyuric, hypoinsulinemic, and dyslipidemic compared with normal mice (Table 1).

3.1. MSC Administration Prevents Renal Failure. We asked whether MSCs were able to prevent renal failure. In order to address this question renal function was assessed in all experimental groups eight weeks after diabetes induction (before MSC administration) and two and eight weeks after MSC administration. As shown in Table 2, DM mice presented increased albumin excretion rate and plasmatic BUN levels at every time point. After 16 weeks from diabetes induction, they reached values of albuminuria 10 times higher and values of plasmatic BUN two times higher than that observed in normal mice. By contrast, DM + MSCs mice maintained low levels of albuminuria and plasmatic BUN (similar to the preMSC administration stage) until the end of the study period.

Plasmatic creatinine levels can be used to show signs of renal function in the end-stage of renal disease [14]. During early-stage post-diabetic induction, the plasmatic level of creatinine did not exhibited significant difference in any experimental group, while this level was significantly higher in DM mice compared with normal mice at the end of the study period (16 weeks after diabetes induction). MSC administration to DM mice maintained the levels of plasmatic creatinine similar to normal mice (Table 2). 


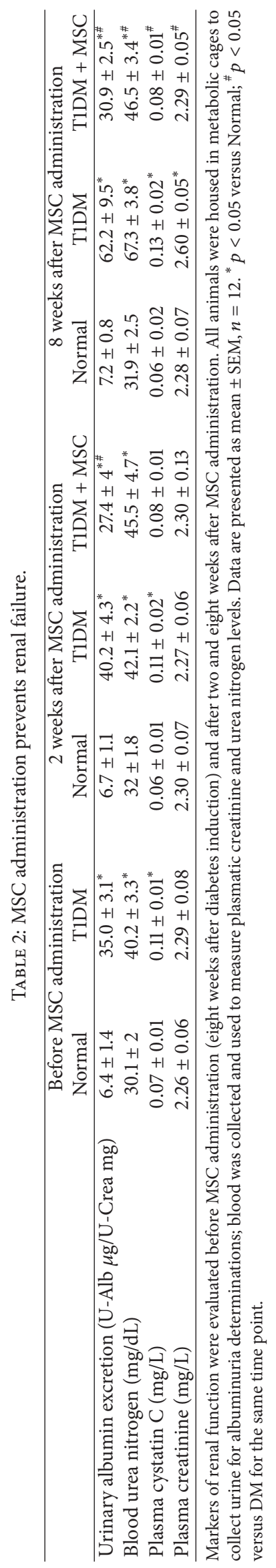


3.2. MSC Administration Prevents Renal Histopathological Changes. To further characterize the therapeutic effect of MSC administration, we analyzed renal morphology. Renal mass index, determined by the kidney weight to body weight ratio, was significantly higher in DM mice compared with normal mice. A significant decrease of this ratio was observed in DM + MSCs mice eight weeks after MSC administration (Table 1).

Histological alterations in kidney tissue were evaluated by conventional PAS and Masson's trichrome staining and by the presence of the renal damage marker $\alpha$-SMA by immunohistofluorescence. PAS stained sections were analyzed two and eight weeks after MSC administration; kidneys from DM mice showed increased extracellular matrix deposition and glomerular hypertrophy (an increase in renal corpuscle area and glomerular tuft area) compared with kidneys from normal mice (Figures 1(a), 1(b), and 1(c)). Kidneys from DM mice also showed cytoplasmic vacuolation in cortical tubular cells (data not shown). By contrast, kidneys from DM + MSCs mice showed decreased mesangial matrix deposition accompanied with a reduction of the renal corpuscle area and glomerular tuft area, maintaining normal values (Figures 1(a), $1(\mathrm{~b})$, and $1(\mathrm{c})$ ). However, tubular cytoplasmic vacuolations were still observed in the kidneys of DM + MSCs mice (data not shown).

The renal damage marker $\alpha$-SMA has been used as an early marker of glomerulosclerosis [33, 40-42]. In accordance with previous reports, immunohistofluorescence signal for $\alpha$-SMA was not detected in normal glomeruli except for smooth muscle cells of efferent and afferent arterioles [14, 33]. Compared with normal mice, the percentage of glomeruli with prominent signal for $\alpha$-SMA in the mesangial area was gradually increased in the kidney of DM mice, leading to an increase in the glomerulosclerosis index (Figures 2(a) and $2(\mathrm{~b}))$. However, the percentage of glomeruli with $\alpha$ SMA immunoreactivity in the kidneys of DM + MSCs mice was significantly reduced at every time point, leading to a reduction in the glomerulosclerosis index (Figures 2(a) and 2(b)). Moreover, the mRNA level of TGF- $\beta$, a prosclerotic cytokine, was significantly reduced two weeks after MSC administration compared with DM mice (Figure 2(c)).

Eight weeks after diabetes induction Masson's trichromic stained sections from DM mice showed morphological alterations which are signal of chronic damage, such as abundant collagen fiber deposition, loss of brush border, flattening of the epithelia, presence of tubular detritus, and a large quantity of dilated tubules compared with normal mice (Figure 2(d)). On the other hand, kidney sections from $\mathrm{DM}+$ MSCs mice showed more conserved morphologies and a significant reduction in the fibrotic area, compared with DM mice (Figures 2(d) and 2(e)). This reduction was also reflected in the mRNA levels of some profibrotic molecules. qRT-PCR studies showed that the expression levels of collagen type I and fibronectin in renal tissue from DM mice were remarkably increased compared with normal mice (Figure 2(f)). Laminin $\beta 1$ expression was also increased in the kidneys from DM mice; however this difference did not reach a statistical significance (Figure 2(f)). All these profibrotic markers showed a tendency to decrease in the kidney of DM + MSCs mice compared with DM mice (Figure 2(f)), suggesting that renal fibrosis was reduced after MSC administration.

3.3. MSC Administration Prevents Renal Ultrastructural Changes. At the ultrastructural level, normal kidneys showed scanty amount of extracellular matrix around mesangial cells and glomerular basement membrane (GBM) with a thickness between 150 and $180 \mathrm{~nm}$ (Figures 3(a) and 3(b)). Furthermore, the kidneys from DM mice showed marked widening of the GBM (range between 230 and $625 \mathrm{~nm}$ ) with segmental "hump-like" localized protrusions of the capillary loops, along with up to $35 \%$ foot process effacement of the podocytes and a significantly increased in mesangial matrix deposition (Figures 3(c) and 3(d)). By contrast, kidneys from DM + MSCs mice showed less extracellular mesangial expansion than DM mice and normal thickness of the GBM and persistent protrusions of the subepithelial side of the GBM (Figures 3(e) and 3(f)). Thus, MSC administration preserves normal renal ultrastructure.

3.4. MSC Administration Maintains the Integrity of the Glomerular Filtration Barrier. The damage caused to the filtration barrier triggers a slow and inexorable decline in renal function that can ultimately result in renal failure. To identify the molecular basis of the renoprotection observed after MSC administration, we evaluated the glomerular capillary lumen, we performed immunostaining for WT-1 and podoplanin, and we measured the expression of nephrin, which are all marker indicatives of the status of the glomerular filtration barrier.

The ratio of glomerular capillary lumen area/glomerular tuft area was calculated at the end of the study period. In normal mice, the glomeruli capillary network was strongly labeled whereas capillary lumen area was greatly reduced in the glomeruli of DM mice. By contrast, the glomeruli of DM + MSCs mice maintained a strong capillary network similar to normal mice (Figures 4(a) and 4(d)).

Podoplanin is localized on cell membranes of podocytes and is involved in the maintenance of the highly specialized structure of the podocytes and its foot processes, which is essential to the normal functioning of the glomerular filtration barrier [34]. Since quantitative western blotting of glomerular protein extract would not show subtle segmental changes in the expression of podoplanin, we performed immunohistofluorescence to detect the glomerular expression of this marker. At the end of the follow up, there was a focal and segmental loss of podoplanin protein in the glomeruli of DM mice, while MSC administration significantly attenuated this loss (Figures 4 (b) and 4(e)). Additionally, the number of podocytes per glomeruli (evaluated by WT-1 staining) was reduced in DM mice; however this difference did not reach statistical significance (data not shown); however, more important than the podocyte number per se is the podocyte number in relation to the territory that each podocyte has to cover. Accordingly, the glomerular volume per podocyte was significantly greater in the glomeruli of DM mice compared with normal animals, 

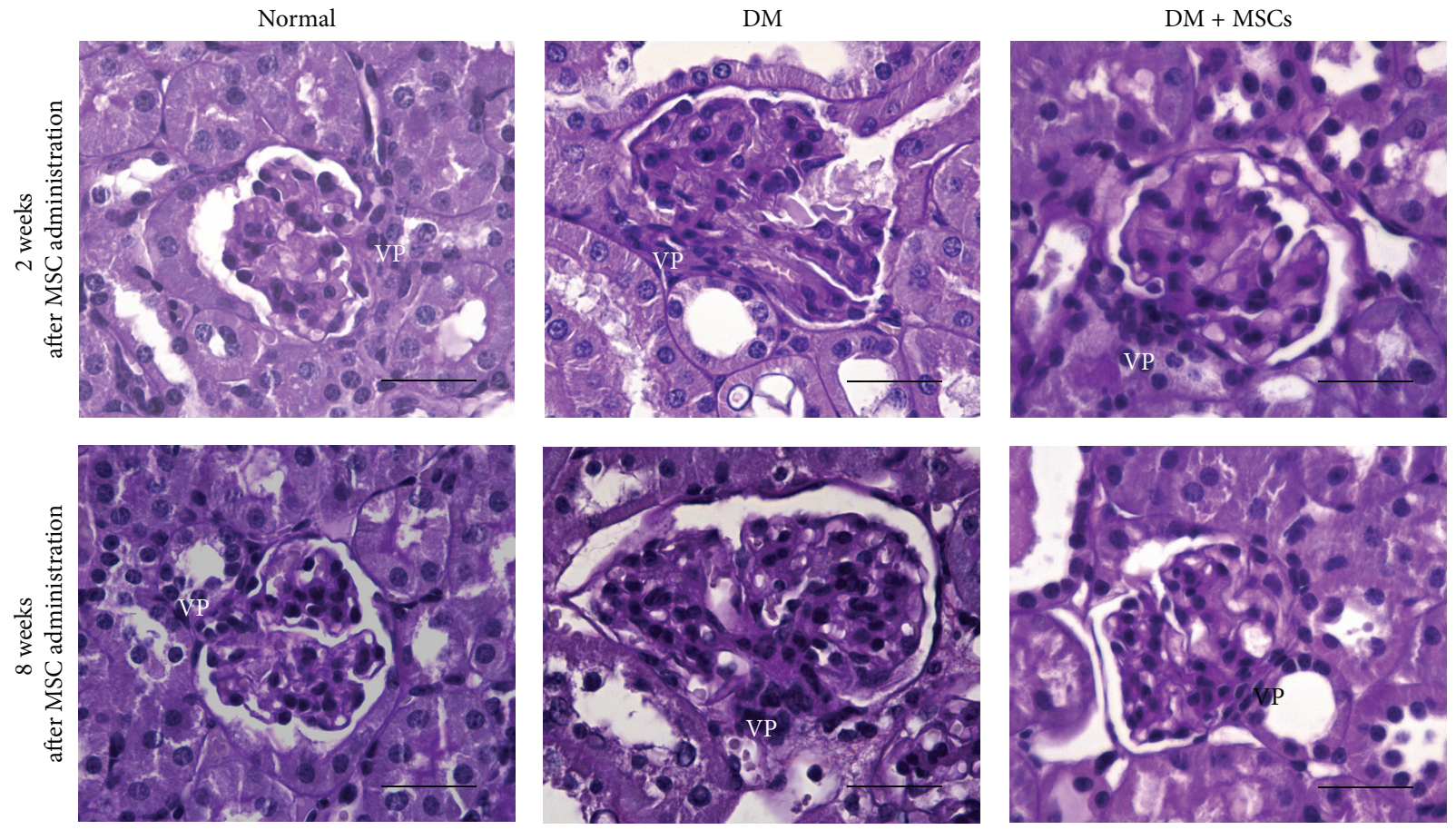

(a)

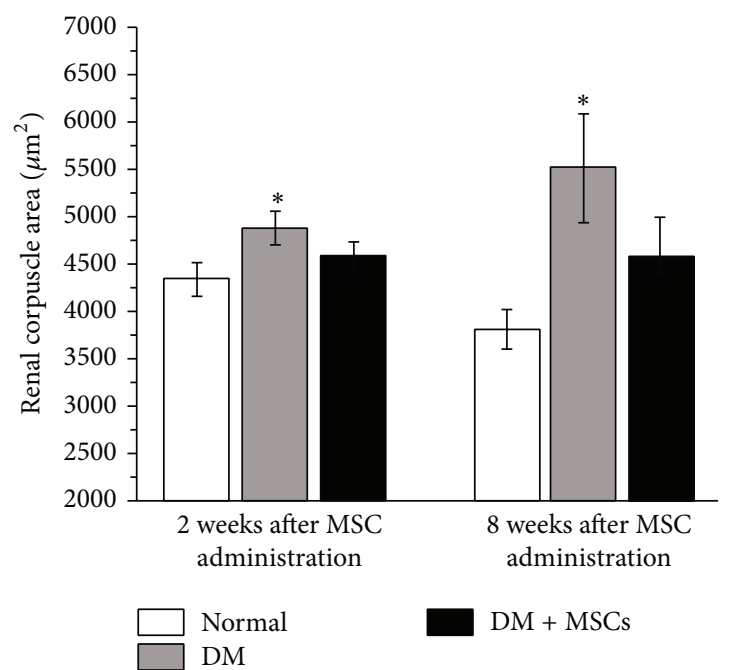

(b)

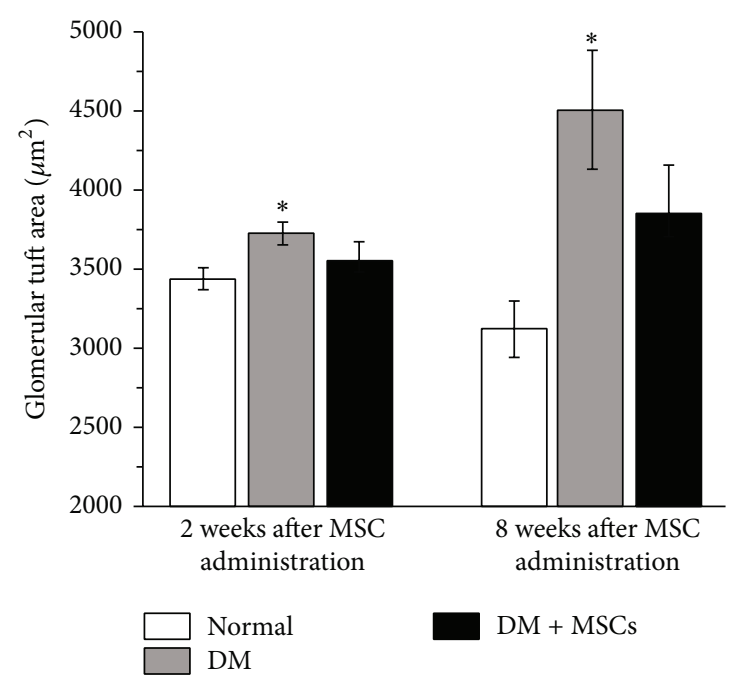

(c)

FIGURE 1: MSC administration reduces glomerular hypertrophic alterations. Representative photomicrographs of kidney sections stained with PAS emphasizing in the glomeruli area, two and eight weeks after MSC administration (a). Quantitative analysis of renal corpuscle area (b) and glomerular tuft area (c) two and eight weeks after MSC administration. Data are presented as mean \pm SEM, $n=8$. ${ }^{*} p<0.05$ versus Normal for the same time point. Bar $=25 \mu \mathrm{m}$.

while in the glomeruli of DM + MSCs mice the glomerular volume per podocyte was significantly reduced compared with DM mice (Figures 4(c) and 4(f)).

Finally, we evaluated the expression of nephrin, which is the principal protein involved in the formation of slit diaphragm in the filtration barrier [43,44]. In line with the above results, qRT-PCR analysis showed that MSC administration significantly attenuated the diabetic-induced decrease of nephrin expression (Figure 4(g)).
3.5. Administered MSCs Do Not Massively Integrate into the Kidneys. In order to evaluate if the therapeutic effect observed after MSC administration could be related to the integration of MSCs into the damaged kidney structures, the renal homing of MSCs ${ }^{\mathrm{GFP}}$ was assessed in DN and normal mice, two weeks and eight weeks after MSC administration. Immunohistofluorescence for GFP demonstrated that, in DM mice at both time points, only few MSCs ${ }^{\text {GFP }}$ were present in the kidney, mainly around renal tubulointerstitium 

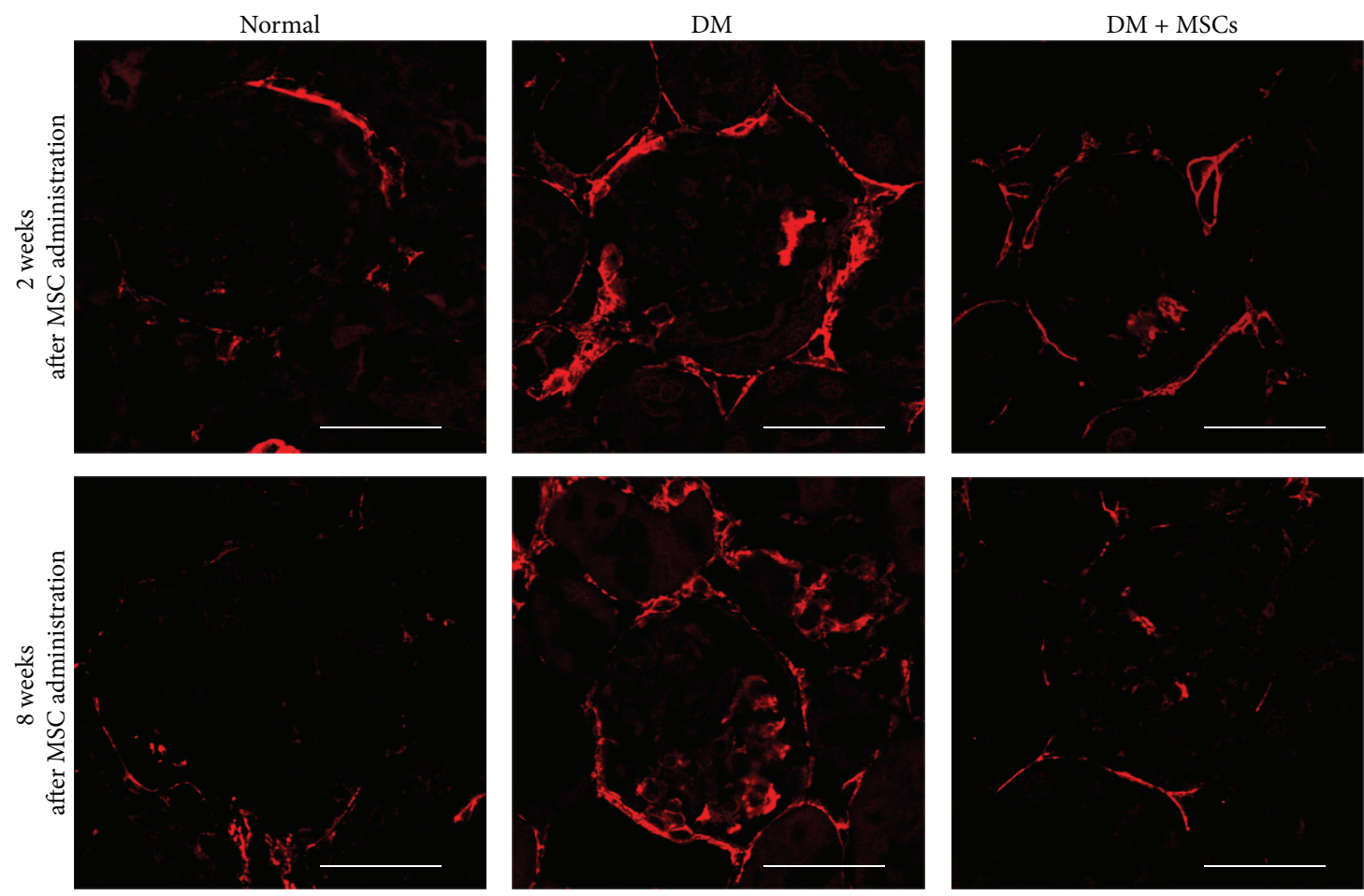

(a)
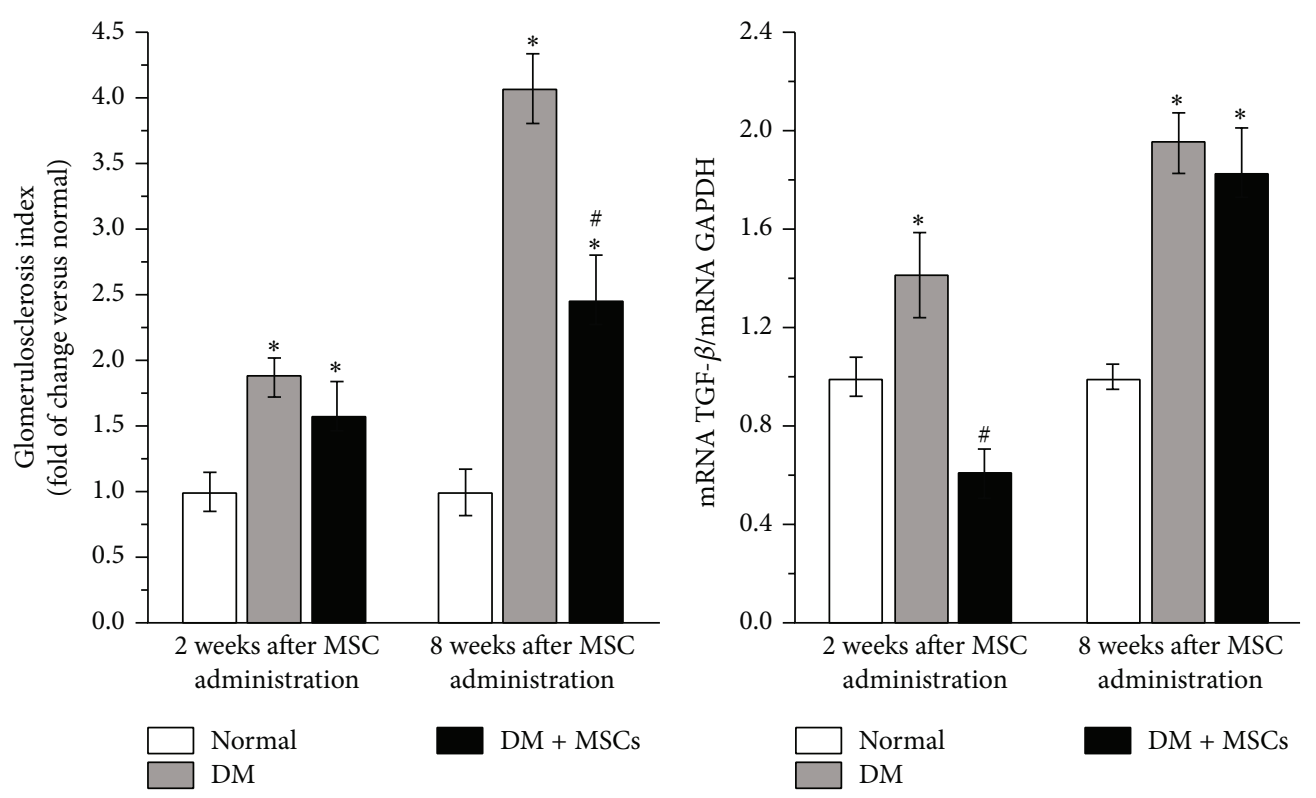

(b)
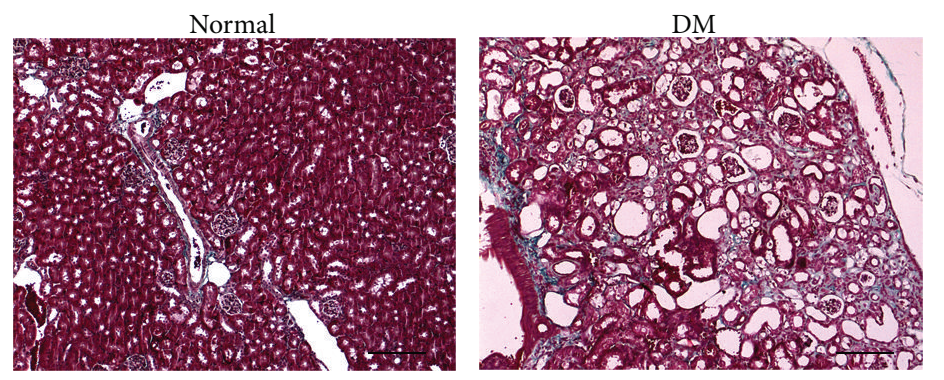

(c)

(d)

Figure 2: Continued. 


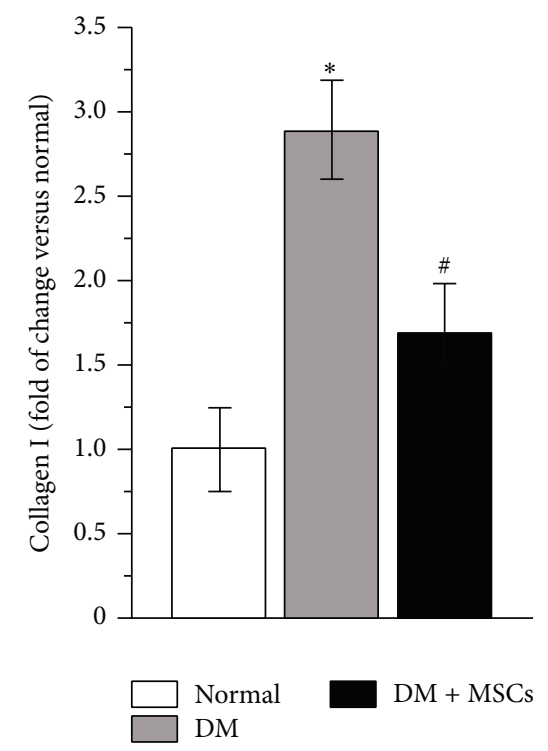

(e)
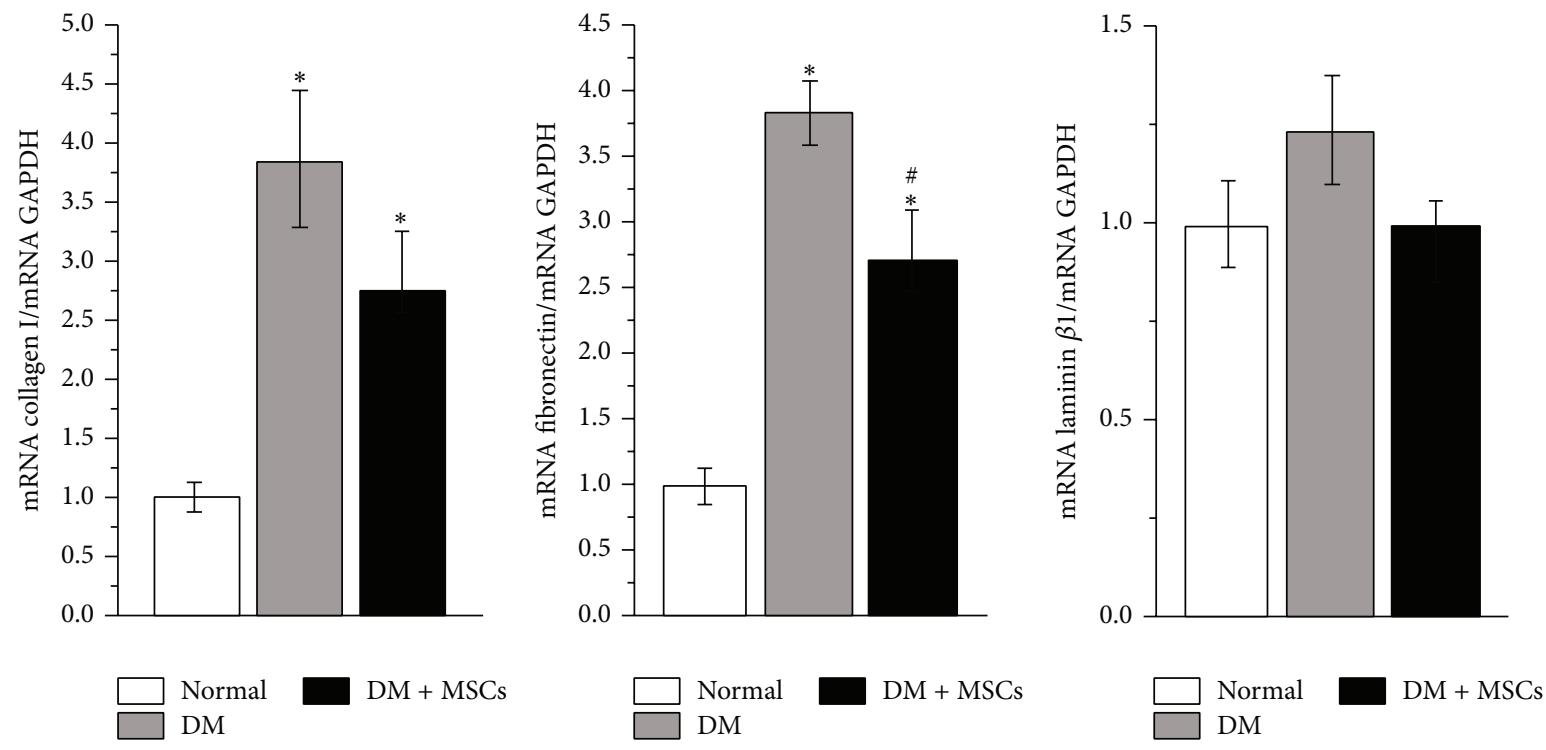

(f)

FIGURE 2: MSC administration prevents renal fibrosis. Representative photomicrographs of kidney sections showing $\alpha$-SMA immunoreactivity in glomeruli, two and eight weeks after MSC administration (a). Quantitative analysis of glomerulosclerosis index evaluated by the percentage of glomeruli exhibiting prominent signal for $\alpha$-SMA in the mesangial area (b). TGF- $\beta$ mRNA levels in renal tissue determined by qRT-PCR (c). Representative photomicrographs of kidney sections stained with Masson's trichrome showing deposition of collagen eight weeks after MSC administration (d). Quantitative analysis of collagen I deposition, evaluated by point-counting method (e). mRNA level of collagen type I, fibronectin, and laminin $\beta 1$ quantified by qRT-PCR eight weeks after MSC administration (f). Data are presented as mean \pm SEM, $n=8 .{ }^{*} p<0.05$ versus Normal; ${ }^{\#} p<0.05$ versus DM for the same time point. $\mathrm{Bar}=150 \mu \mathrm{m}$.

(Figures 5(a) and 5(b)). No MSCs ${ }^{\text {GFP }}$ were found in the kidneys of normal mice (data not shown).

\subsection{MSC Administration Triggers a Proregenerative Microen-} vironment. To understand if the therapeutic effects observed after MSC administration could be related to the generation of a proregenerative microenvironment, the rate of cell proliferation in the kidneys was determined by the quantification of the nuclear expression of Ki-67 and glomerular and tubular sections were analyzed independently. The glomeruli of DM + MSCs mice presented higher proliferation rate two weeks after MSC administration compared with normal and DM mice (Figure 6(a) and Supplementary Figure 1). At tubular level, DM mice showed a significant increase in the proliferation rate compared with normal mice, probably associated with a compensatory response to chronic injury. $\mathrm{Nev}$ ertheless, the administration of MSCs significantly increased this response (Figure 6(b) and Supplementary Figure 1). 


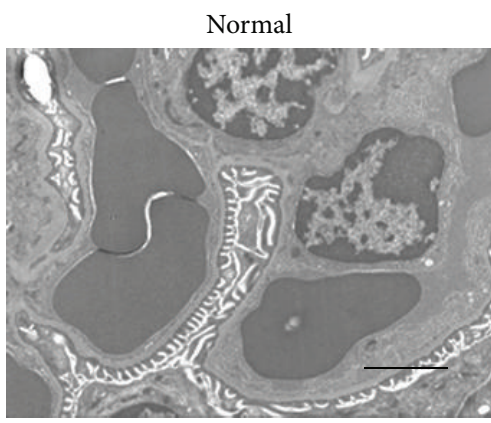

(a)

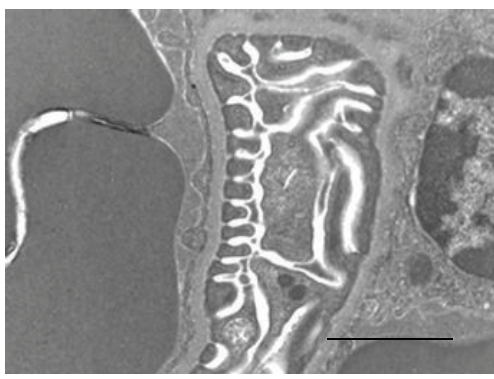

(b)

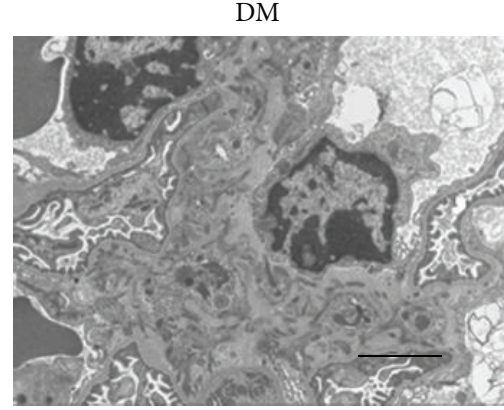

(c)

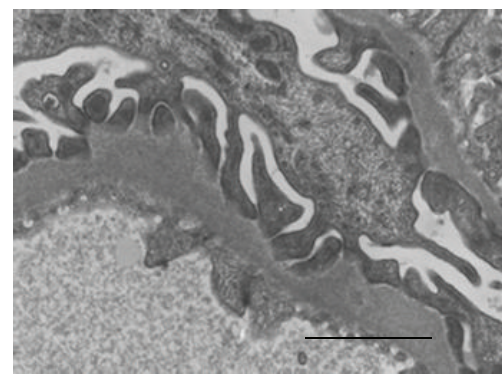

(d)

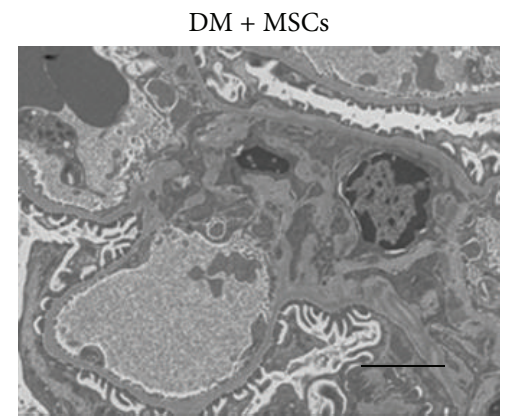

(e)

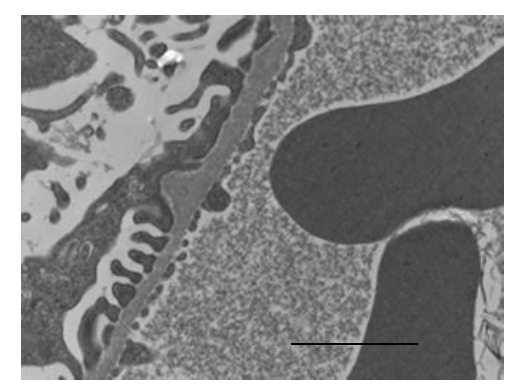

(f)

FIGURE 3: MSC administration prevents renal ultrastructural alterations. Electron photomicrographs of representative glomeruli from normal mice (a and b), DM mice ( $c$ and d), and DM + MSCs mice (e and f), showing marked (c) and moderate (f) increase of extracellular mesangial matrix, overt irregularities and thickening of the GBM (d), and persistent "hump like" protrusions (f). Picture magnification: (a), (c), and (e) $\times 6,000$; (b), (d), and (f) $\times 16,500$. Bars magnifications: (a), (c), and (e) 2,000 nm; (b), (d), and (f) 1,000 nm.

The apoptotic index was evaluated in glomerular and tubular sections. As expected, DM mice showed a marked increase in the number of apoptotic nuclei in both areas (Figures 6(c) and 6(d) and Supplementary Figure 2). Nevertheless, this increase was significantly reduced in the kidney of DM + MSCs mice after two weeks and eight weeks after MSC administration.

MSCs are known to produce, both in vitro and in vivo, a broad range of trophic factors that have been associated with tissue regeneration by induction of proliferation and reduction of apoptosis [45]. Systemic bFGF and EGF levels were markedly reduced in DM mice compared with normal mice, while the administration of MSCs restored the normal plasmatic level of both regenerative factors (bFGF two weeks after MSC administration and EGF two and eight weeks after MSC administration) (Figures 7(a) and 7(b)). Plasmatic HGF levels were increased both in DM mice and DM + MSCs mice compared with normal mice (Figure $7(\mathrm{c})$ ) and plasmatic levels of VEGF and ET1 were unchanged in any experimental condition (data not shown).

The renal tissue has high regeneration capacity associated, at least in part, to the secretion of trophic factors [46]. To evaluate if MSC administration could induce a proregenerative microenvironment, the local expression of trophic factors was evaluated by qRT-PCR. In accordance with plasmatic levels, the renal expression of EGF decreased significantly in diabetic animals and MSC administration restored normal EGF mRNA levels (Figure 7(e)). Additionally, diabetic mice presented high mRNA levels of bFGF and HGF in the kidney; however, MSC administration significantly enhanced this response (Figures $7(\mathrm{~d})$ and $7(\mathrm{f})$ ).

3.7. MSC Administration Reduces Oxidative Stress Damage. Oxidative stress plays an important role at both early and late stages of DN [6] and it has been postulated that MSCs could efficiently scavenge reactive species [47]. Total oxidative species were evaluated in renal tissue, two and eight weeks after MSC administration. The diabetic condition induced a significant increase in the amount of total oxidative species in the kidney that was significantly reduced eight weeks after MSC administration (Figure 8(a)). The reduction in ROS level was correlated with a significant reduction in lipid peroxidation level (Figure 8(b)) and protein oxidative damage (Figure $8(\mathrm{c})$ ). By contrast, the DNA oxidative damage remained significantly elevated irrespective of MSC administration (Figure 8(d)).

Total antioxidant capacity was reduced in DM mice, with a trend to be higher in the treated mice eight weeks after MSC administration (Figure 8(e)).

3.8. MSC Administration Prevents Renal Inflammation. The inflammatory influx is present in the diabetic kidney and is one of the driving forces to induce tissue damage $[48,49]$. Multifocal inflammatory cellular foci were observed in the kidney of DM mice (Figure 9(a)). By contrast, no leukocyte infiltration foci were observed in the kidney of DM + MSCs mice (Figure 9(a)). Since macrophages account for most of the infiltrating leukocytes (>90\%) [30] and they correlate 

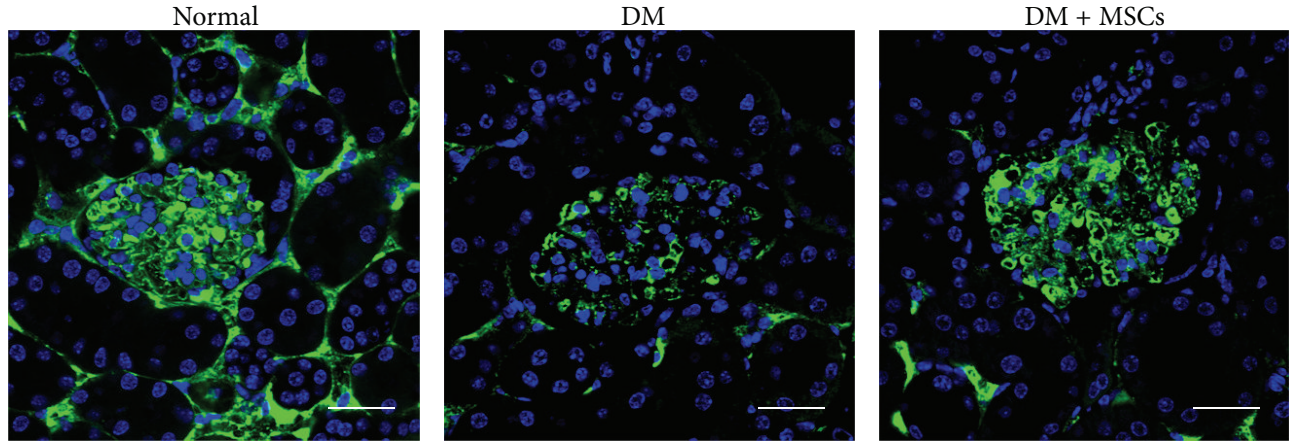

(a)
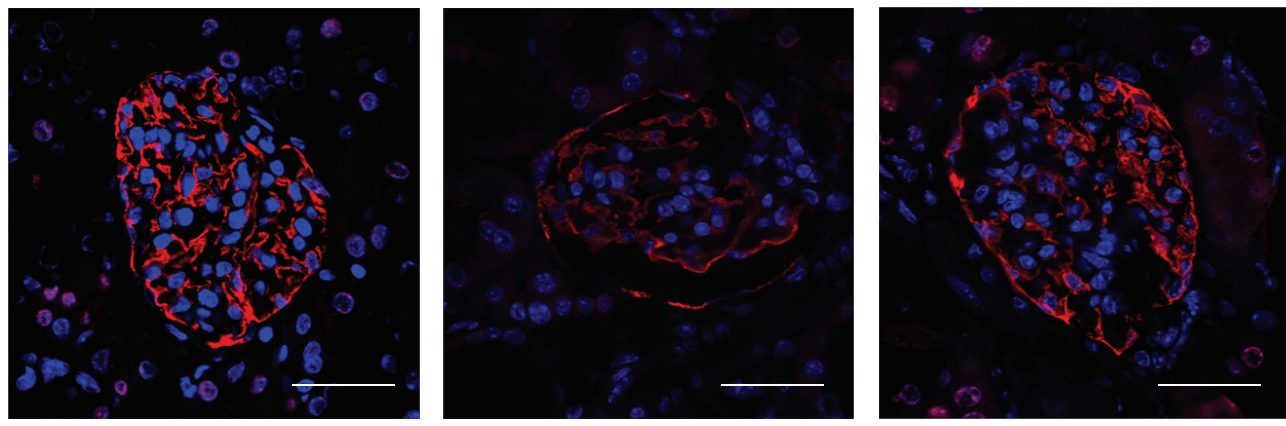

(b)
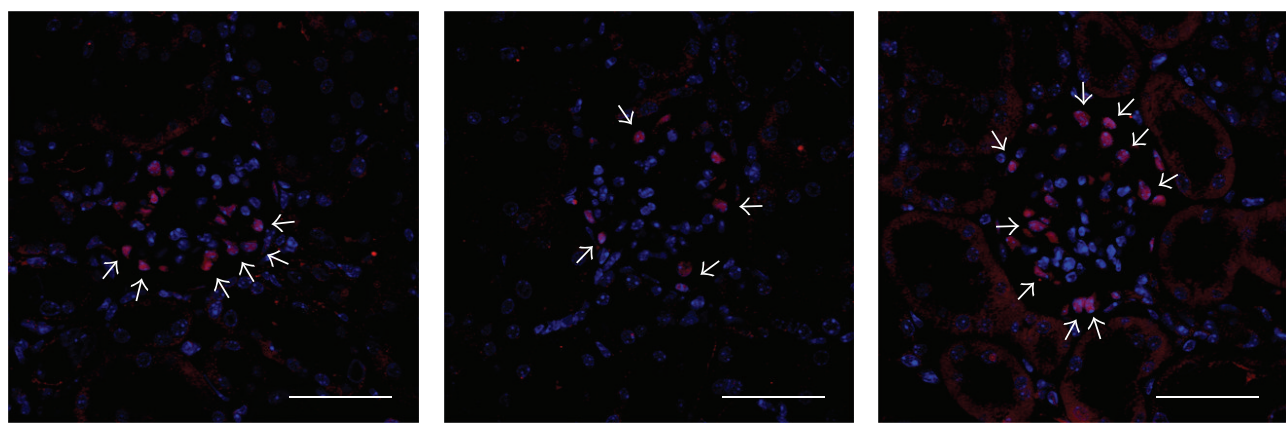

(c)

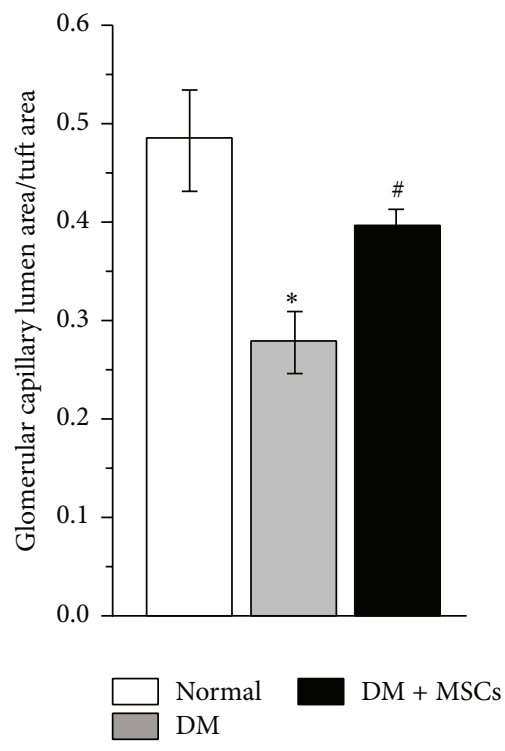

(d)

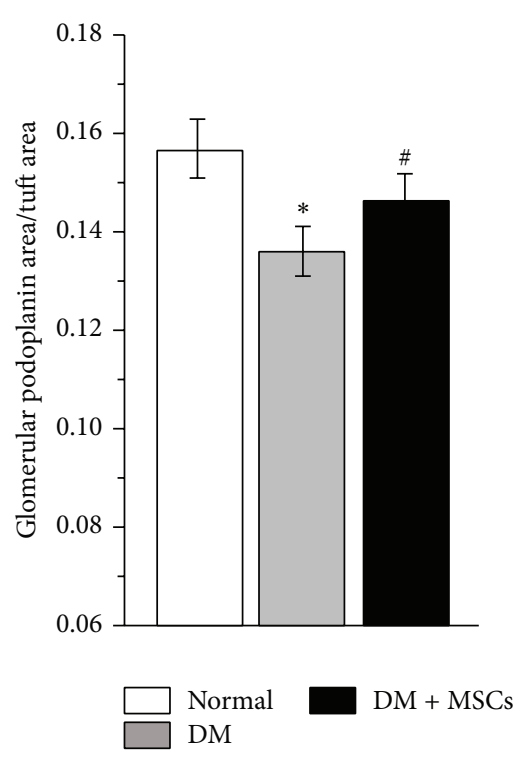

(e)

Figure 4: Continued. 


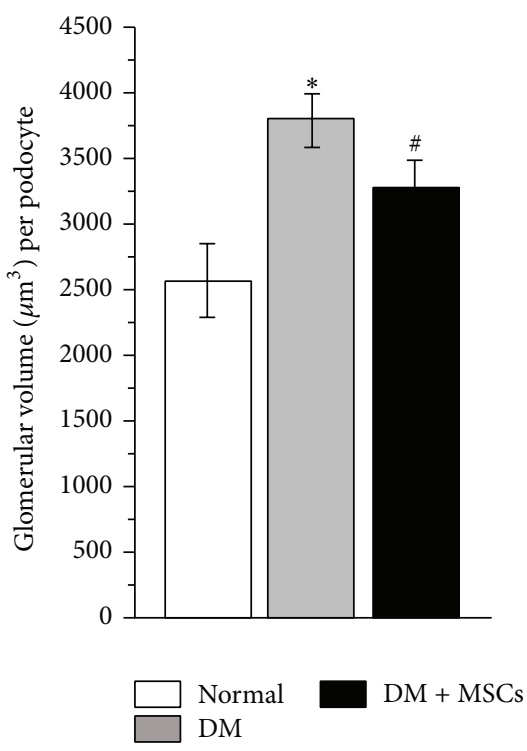

(f)

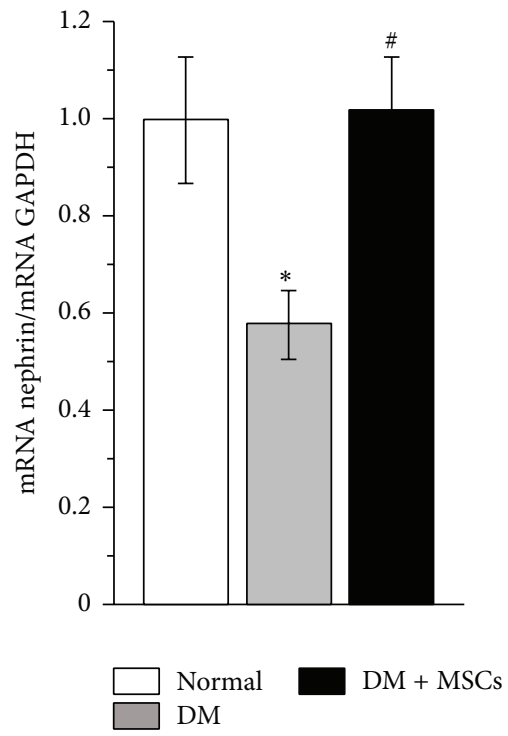

(g)

FIGURE 4: MSC administration maintains the integrity of the glomerular filtration barrier. Representative photomicrographs of kidney sections eight weeks after MSC administration showing glomerular capillary lumen area (green), labeled by the endovenous administration of $2 \times 10^{6}$ MW FITC-dextran (a), glomerular immunoreactivity of podoplanin (red) to evaluate podocyte foot processes integrity (b), and glomerular immunoreactivity of WT-1 (nuclei in red) to evaluate glomerular podocytes (white arrows) (c). In all cases total nuclei were counterstained with DAPI (blue). Quantitative analysis of capillary lumen area normalized by glomerular tuft area (d); glomerular podoplanin area normalized by glomerular tuft area (e); and glomerular volume per podocyte (f). mRNA level of nephrin quantified by qRT-PCR (g). Data are presented as mean \pm SEM, $n=8 .{ }^{*} p<0.05$ versus Normal; ${ }^{*} p<0.05$ versus DM for the same time point. Bar $=25 \mu \mathrm{m}$.

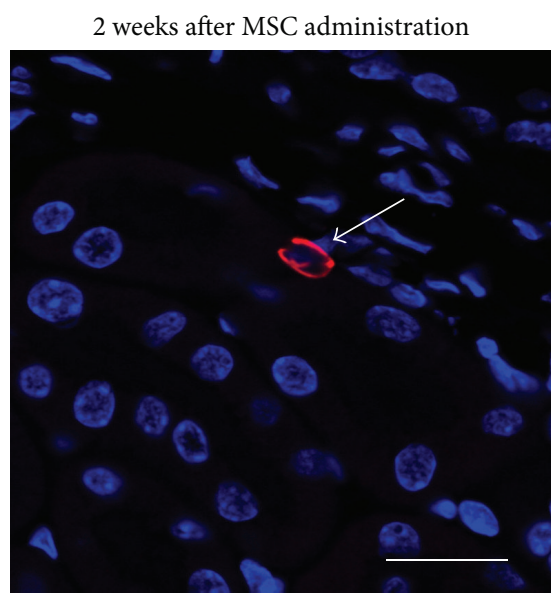

(a)

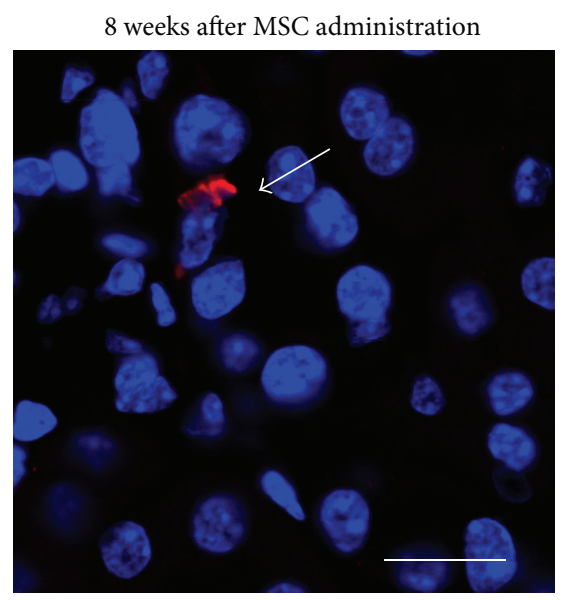

(b)

FIGURE 5: Administered MSCs do not massively integrate into the kidney structure. Two and eight weeks after MSC administration MSC ${ }^{\text {GFP }}$ were localized by confocal microscopy. Representative photomicrographs of kidney sections form DM mice showing the localization of MSCs $^{\text {GFP }}$, white arrows indicate donor cells immunolabeled with anti-GFP-Alexa555 (red); cell nuclei were counterstain with DAPI (blue). Bars $=15 \mu \mathrm{m}$.

with increased levels of albuminuria and plasma creatinine $[50,51]$, F4/80 cells in renal tissue were evaluated. In accordance with the above result, diabetic animals presented an increased number of macrophages per sections, and this was significantly reduced by MSC administration (Figures 9(b) and $9(\mathrm{c})$ ).

MSCs have been recognized as immunomodulatory cells with potent immunosuppressive properties [13]. Based on 


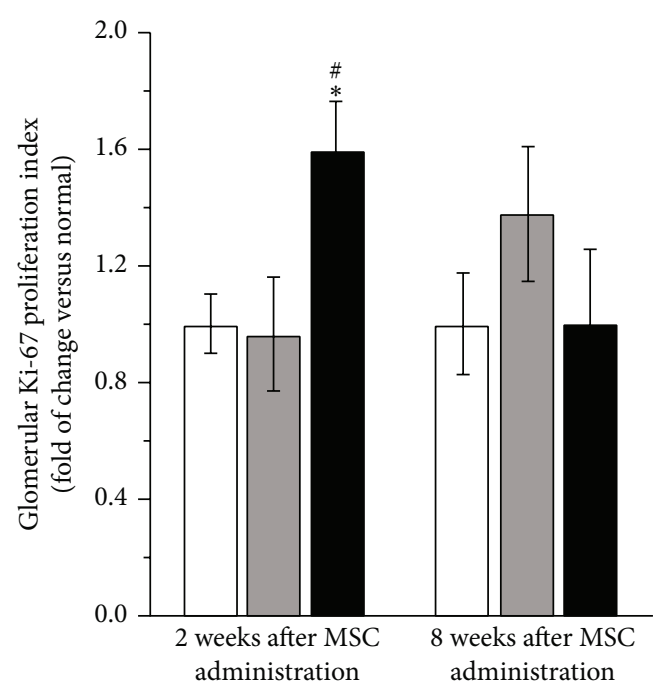

(a)

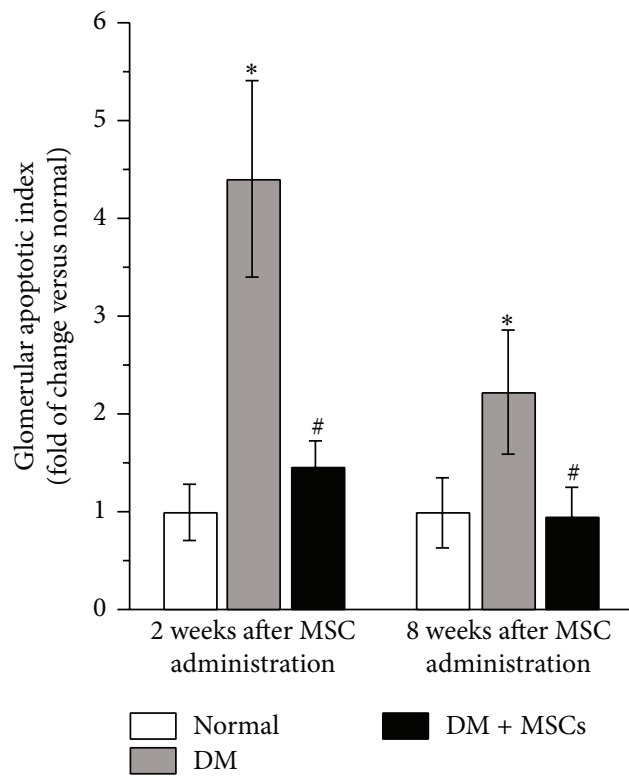

(c)

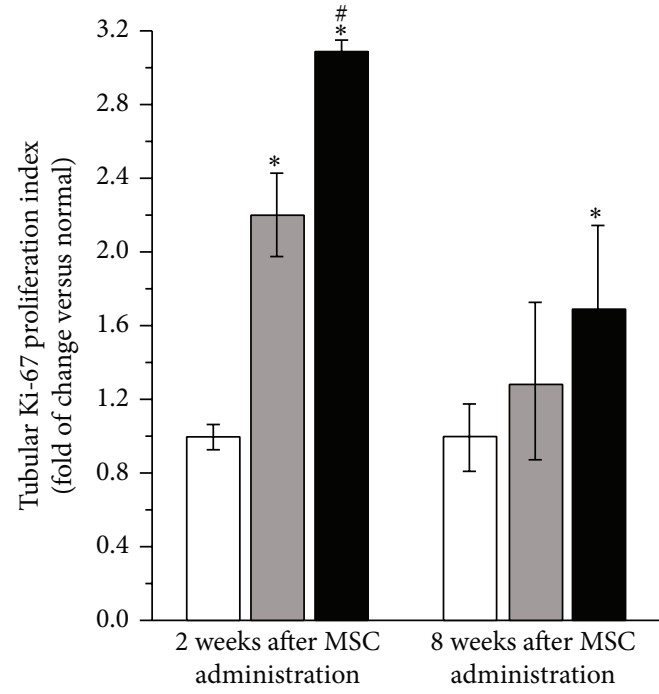

(b)

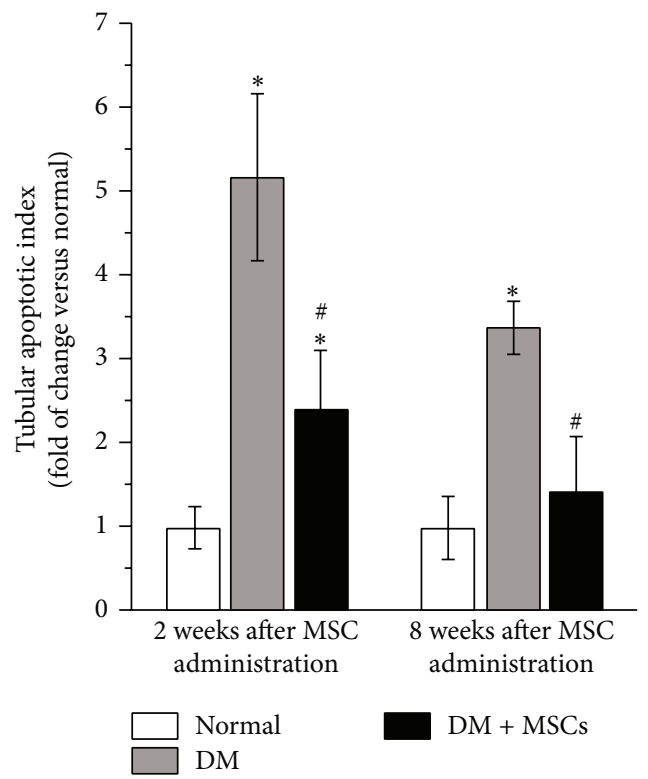

(d)

FIGURE 6: MSC administration induces kidney tissue regeneration. Quantitative analysis of the Ki-67 proliferation index in glomeruli (a) and tubules (b) two and eight weeks after MSC administration. Quantitative analysis of the apoptotic index in glomeruli (c) and tubules (d) two and eight weeks after MSC administration. Data are presented as mean $\pm \mathrm{SEM}, n=8,{ }^{*} p<0.05$ versus Normal; ${ }^{*} p<0.05$ versus DM for the same time point.

these properties, we measured the serum levels and the renal expression of cytokines related to proinflammatory and antiinflammatory responses.

The administration of MSCs did not change the plasmatic level of the proinflammatory cytokines TNF- $\alpha$ and IL-1 $\beta$ (data not shown). However, MSC-treated mice showed a plasmatic cytokine profile compatible with a Th2 polarized immune response, since plasmatic levels of IL6, IL-4, and IL10 were restored, compared with DM mice (Figures 9(d), 9(e), and $9(\mathrm{f}))$.

The same pattern was observed in renal tissues, since MSC-treated animals showed a renal cytokine expression profile compatible with a Th2 polarized immune response, with a high expression of IL-4 and IL-10 (Figures 9(g) and 9(h)). Therefore, MSC administration induces a protective microenvironment.

\section{Discussion}

The major findings of this study were that MSC administration preserved renal function and ameliorate histopathological alterations in an animal model of severe diabetes mellitus. The possible mechanisms underlying these effects involved the temporal inhibition of the TGF- $\beta$ expression 


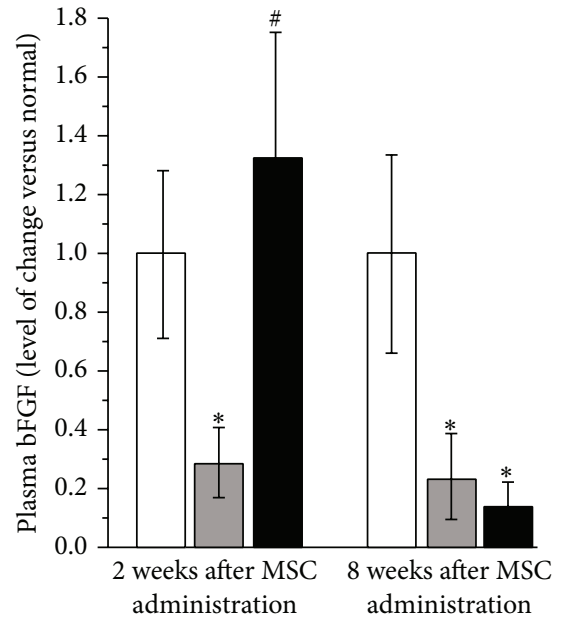

(a)

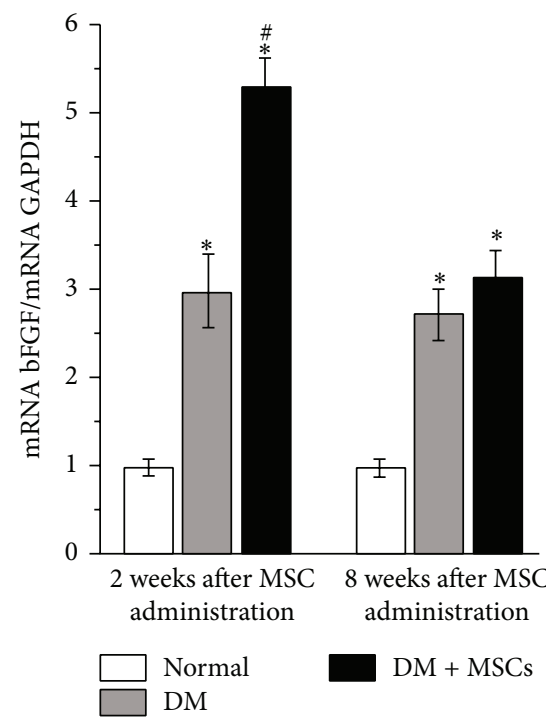

(d)

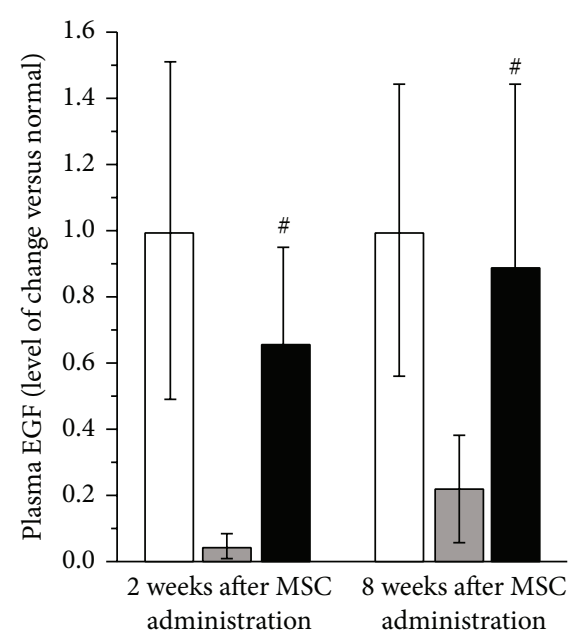

(b)

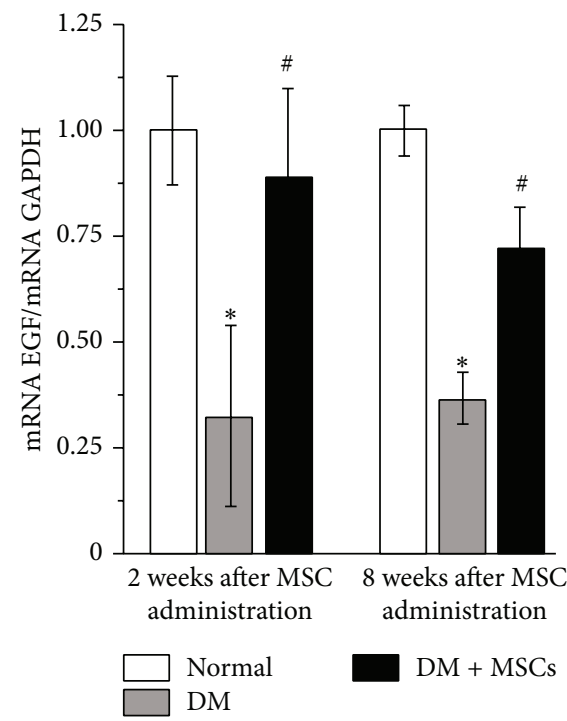

(e)

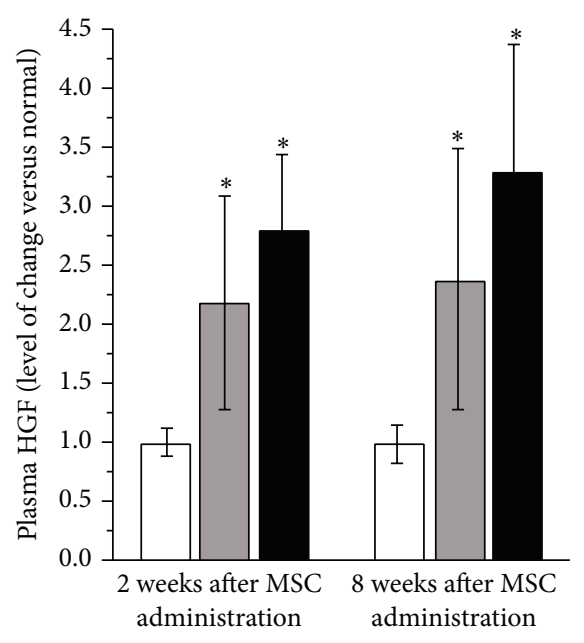

(c)

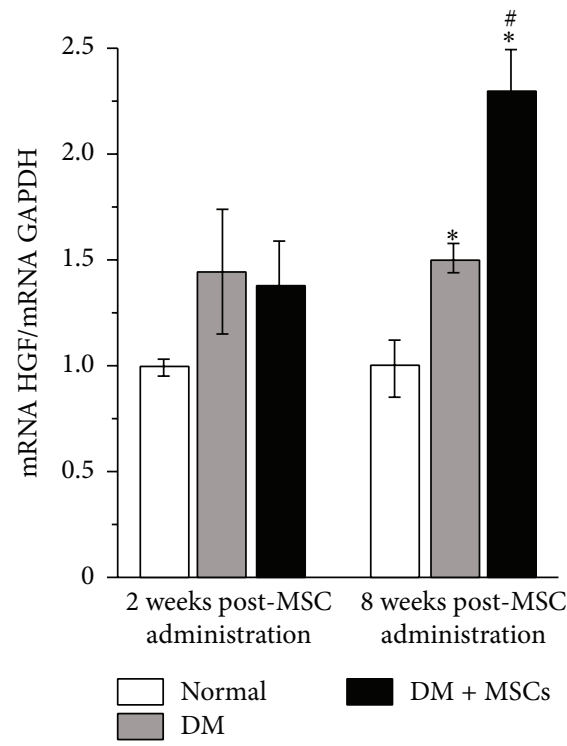

(f)

FIGURE 7: MSC administration increases local and systemic levels of proregenerative factors. Quantitative analysis of plasmatic levels of bFGF (a), EGF (b), and HGF (c) two and eight weeks after MSC administration determined by Luminex Multiplex system. Renal mRNA levels of bFGF (d), EGF (e), and HGF (f) quantified by qRT-PCR, two and eight weeks after MSC administration. Data are presented as mean \pm SEM, $n=8 .{ }^{*} p<0.05$ versus Normal; ${ }^{*} p<0.05$ versus DM for the same time point.

and the triggered of a proregenerative microenvironment, which include the production of protective trophic factors and the reduction of both the oxidative stress damage and the proinflammatory response in the kidney.

Using an animal model of nonimmunological severe diabetes mellitus induced by the administration of a single high dose of STZ $(200 \mathrm{mg} / \mathrm{kg})$, we previously showed that the administration of multiple doses of MSCs was able to prevent albuminuria development despite the persistence of hyperglycaemia [21] suggesting a direct effect of MSCs in the prevention of renal damage. In the present study, using the same animal model we further characterize the effects of MSC administration on renal function and structure, along with the possible mechanisms associated with the therapeutic effects.

MSC administration effectively reduced urinary albumin excretion and plasmatic BUN and creatinine levels. The preservation of renal function lasted at least up to the end of the follow-up study (eight weeks after MSC administration). This improvement in renal function was clearly associated with the preservation of renal structure, since untreated diabetic mice presented glomerular hypertrophy, mesangial expansion, tubular dilatation, glomerulosclerosis, tubulointerstitial fibrosis, and GBM thickening, while the administration of MSCs prevented all these histopathological alterations. 


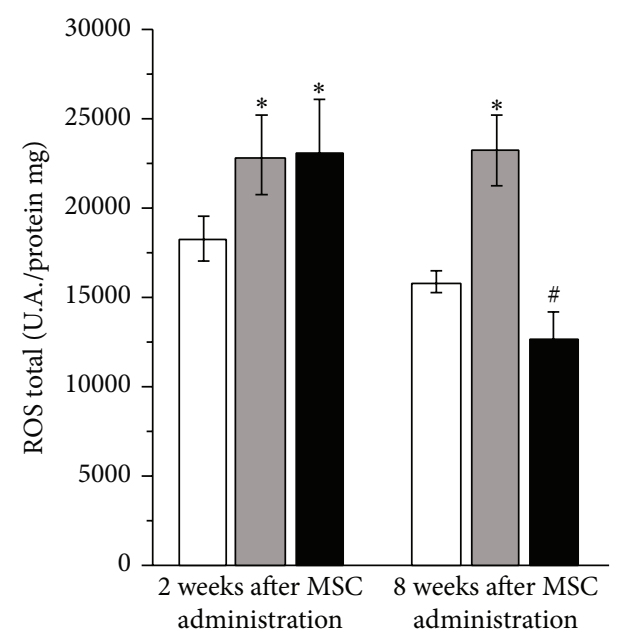

(a)

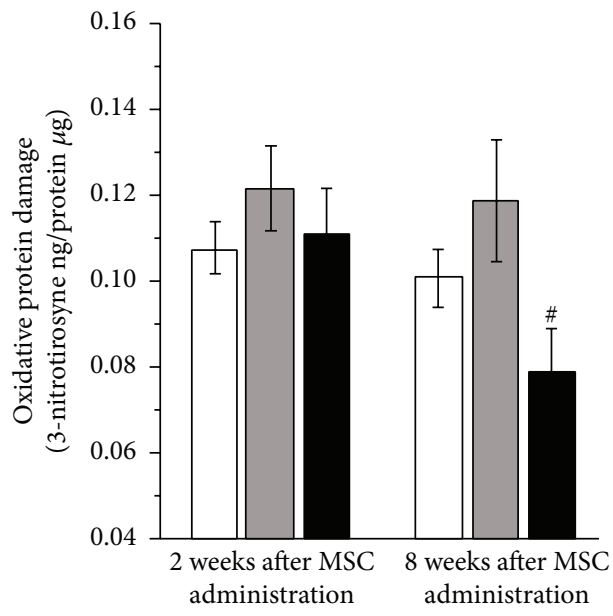

(c)

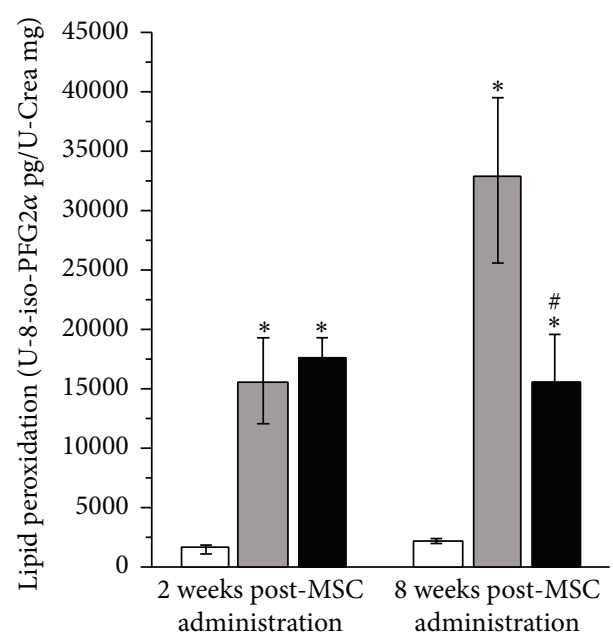

(b)

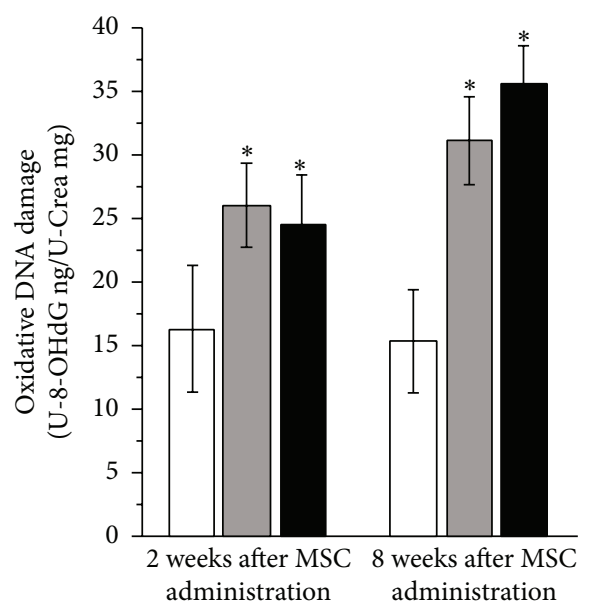

(d)

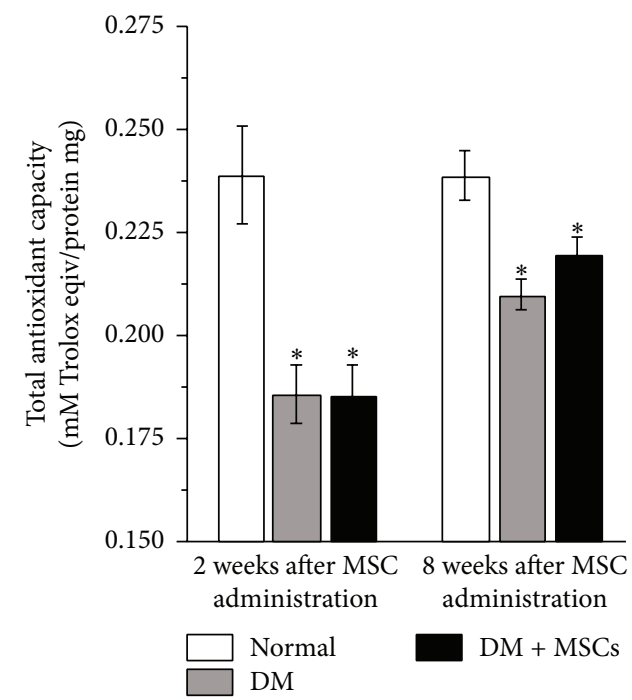

(e)

FIGURE 8: MSC administration reduces oxidative stress. Quantitative analysis of total reactive oxygen species expressed as total ROS per mg of kidney proteins (a); lipid peroxidation level expressed as pg of urinary 8-iso-PFG2 $\alpha$ per mg of urinary creatinine (b); oxidative protein damage level expressed as ng of 3-nitrotyrosine per $\mu \mathrm{g}$ of kidney proteins (c); oxidative DNA damage level expressed as ng of urinary 8-OHdG per mg of urinary creatinine (d); and total antioxidant capacity expressed as mM of Trolox equivalents per mg of kidney proteins (e) two and eight weeks after MSC administration. Data are presented as mean $\pm \mathrm{SEM}, n=8$. ${ }^{*} p<0.05$ versus Normal; ${ }^{*} p<0.05$ versus DM for the same time point. 
Normal
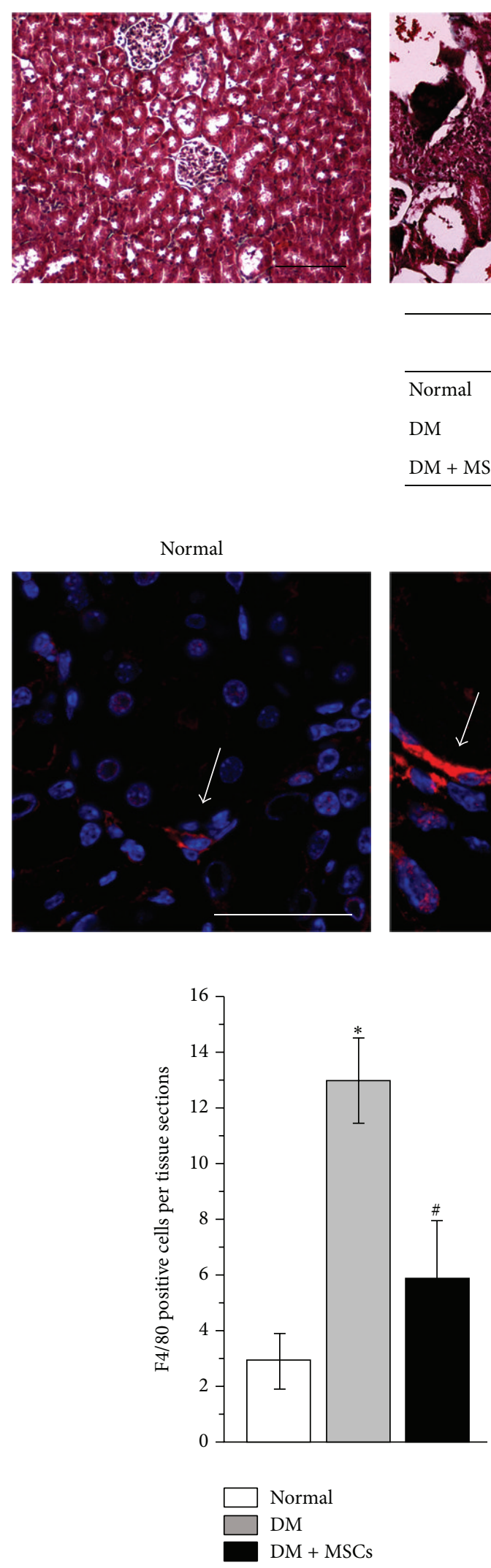

(c)
DM
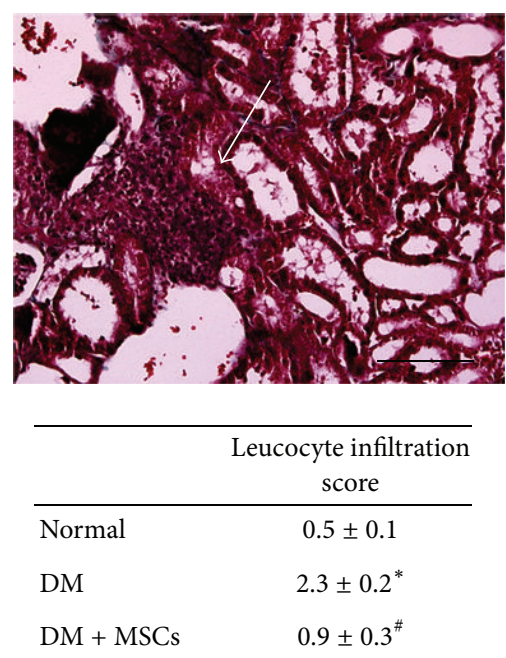

(a)

DM

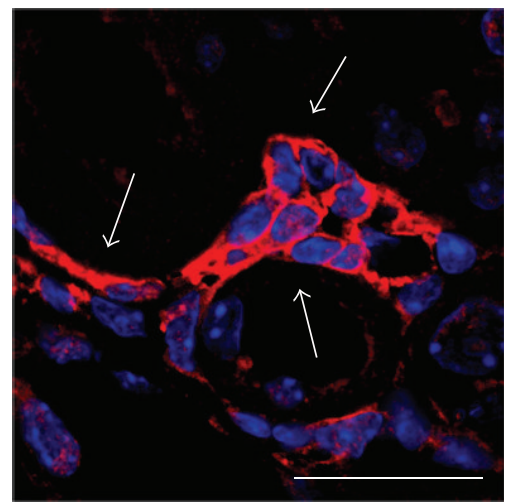

(b)
$\mathrm{DM}+\mathrm{MSCs}$

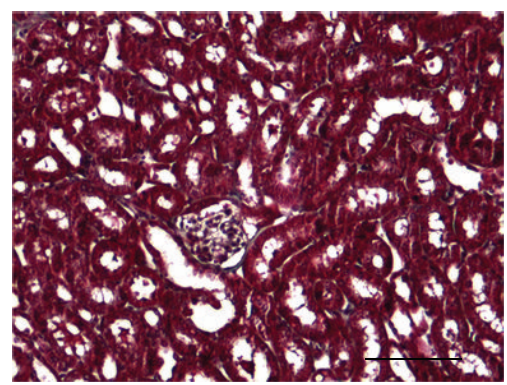

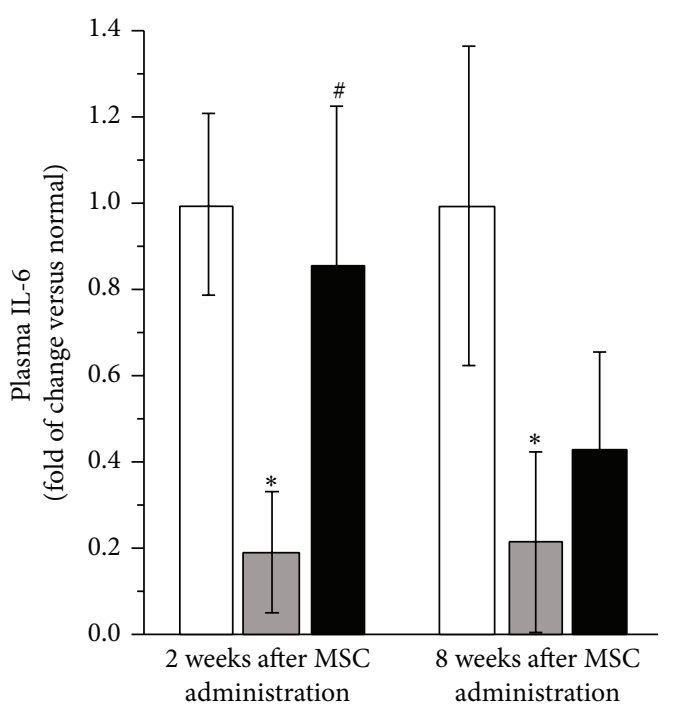

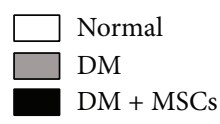

(d)

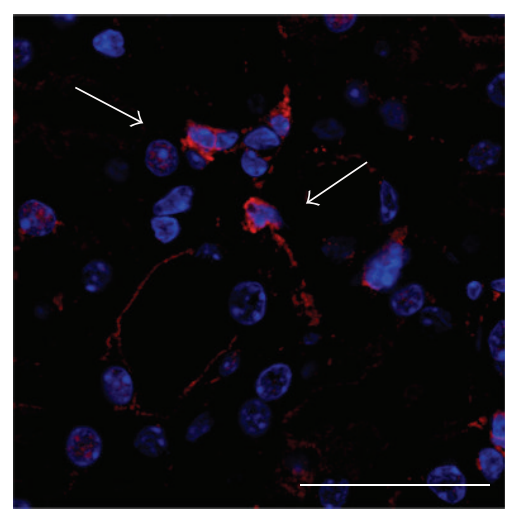

$\mathrm{DM}+\mathrm{MSCs}$ 


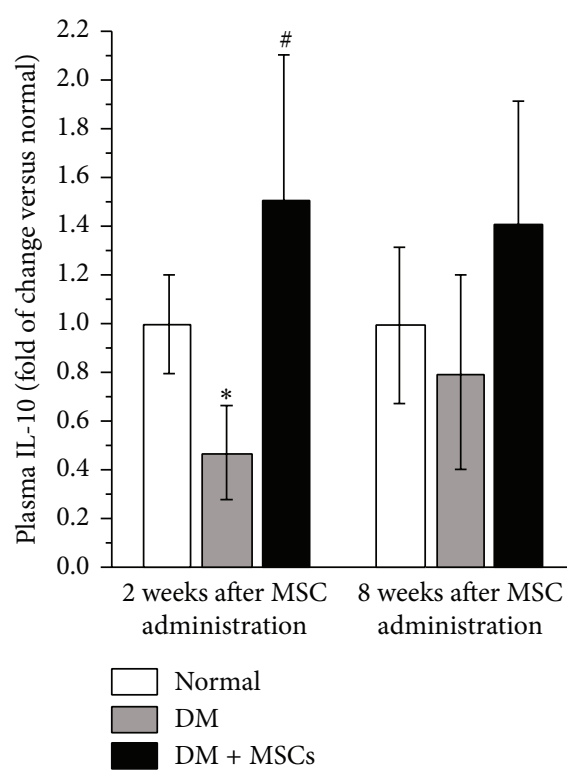

(e)

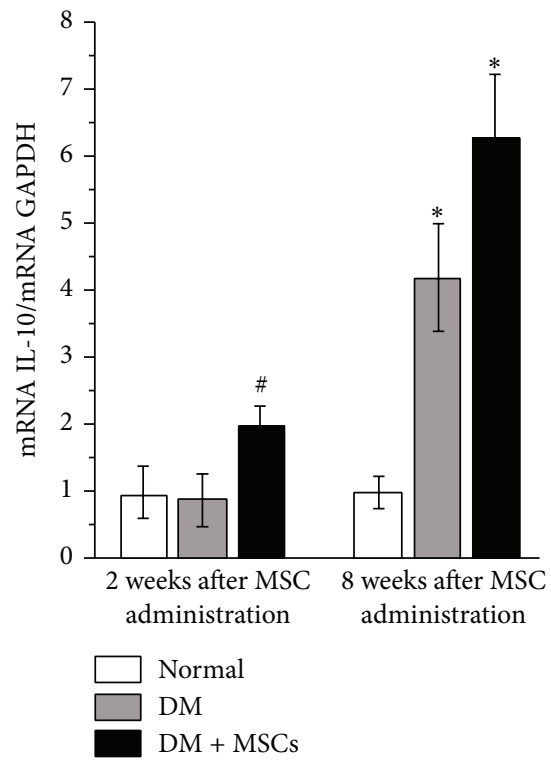

(g)

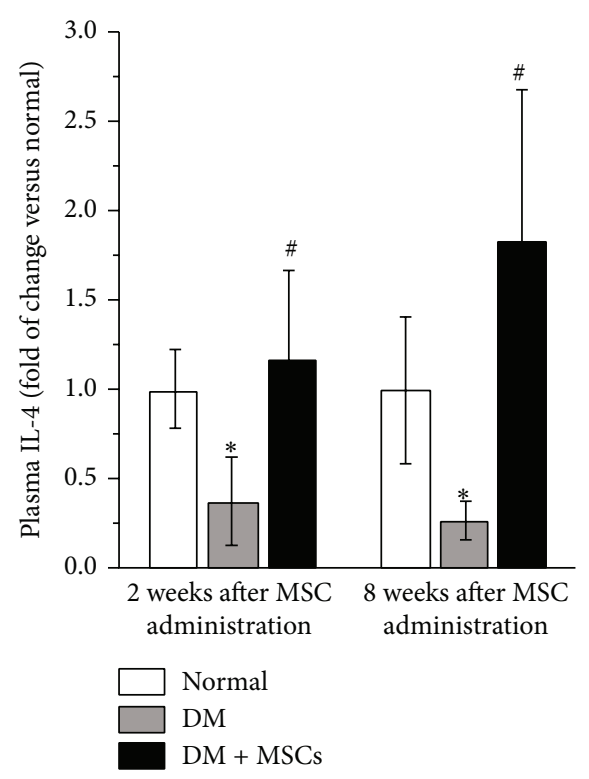

(f)

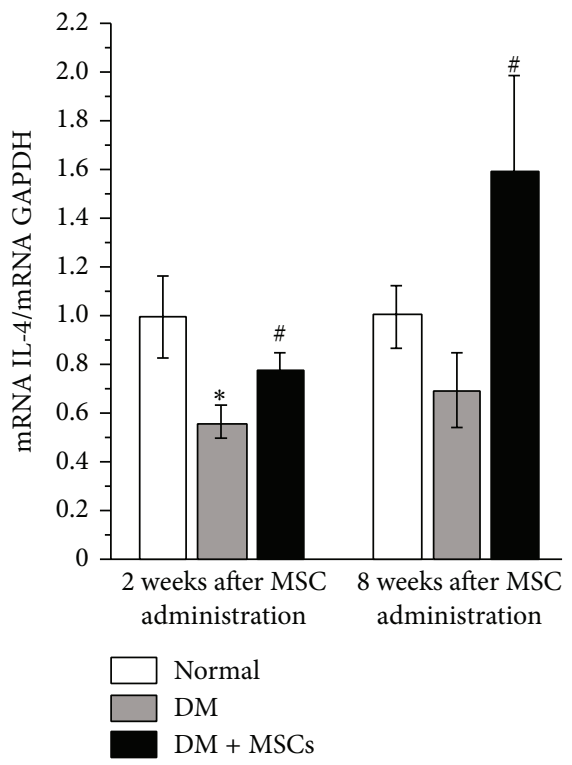

(h)

FIGURE 9: MSC administration prevents renal inflammation. Representative photomicrographs of kidney sections showing inflammatory infiltrates (white arrow) eight weeks after MSC administration. Bar $=100 \mu \mathrm{m}$ (a). Representative photomicrographs of kidney sections showing macrophages (white arrows) (F4/80-red) eight weeks after MSC administration. Barr $=40 \mu \mathrm{m}$ (b). Nuclei were counterstained with DAPI (blue). Quantitative analysis of macrophages per tissue section eight weeks after MSC administration (c). Quantitative analysis of plasmatic levels of the anti-inflammatory cytokines IL-6 (d), IL-10 (e), and IL-4 (f) determined by the Luminex Multiplex system two and eight weeks after MSC administration. Renal mRNA levels of IL-10 (g) and IL-4 (h) quantified by qRT-PCR, two and eight weeks after MSC administration. Data are presented as mean \pm SEM, $n=8,{ }^{*} p<0.05$ versus Normal; ${ }^{*} p<0.05$ versus DM for the same time point.

TGF- $\beta$ upregulation is considered one of the main factors involved in the development and progression of $\mathrm{DN}$ [8]. It stimulates renal cell hypertrophy and extracellular matrix deposition, which causes GBM thickening, glomerular capillary occlusion, and may promote podocyte apoptosis or detachment [35]. In the present severe diabetes mellitus model, we observed an early reduction in the renal expression of TGF- $\beta 1$ after MSC administration, suggesting that glomerulosclerosis and renal interstitial fibrosis were efficiently prevented. The same observation was made in diabetic spontaneous hypertensive rats where the inhibition of TGF- $\beta$ expression by Tranilast, an antiallergic drug that impedes the release of cytokines from immune cells, led to a reduction in glomerular hyperfiltration and glomerular tuff 
area expansion despite persistent hyperglycaemia [52]. In the same line, in vitro and in vivo studies showed that MSCs could inhibit the upregulation of TGF- $\beta$ expression stimulated by high glucose in mesangial cells by the secretion of trophic factors [53]. Thus, we can assume that the early modulation of TGF- $\beta$ expression after MSC administration is related, at least in part, to a reduction in kidney fibrosis.

Under diabetic condition, high glucose levels compromise the integrity of the glomerular filtration barrier via effacement of the podocyte foot processes and loss of podocytes from the glomerular basement membrane. The damage caused to the filtration barrier triggers a slow and inexorable decline in renal function that can ultimately result in renal failure [54-56]. Podoplanin is a glycoprotein expressed on the base of podocyte foot processes and is involved in the maintenance of the highly specialized structure of the podocytes and its foot processes during hypertrophy [34]. In great contrast to the general pattern of most of the podocyte-associated proteins, podoplanin has showed changes in expression with clear temporal association to the development of proteinuria [57]. In the same way, nephrin is the principal protein involved in the formation of slit diaphragm of the filtration barrier [43, 44, 58, 59]. To identify the molecular basis of the renoprotection observed after MSC administration, we performed immunostaining for WT-1 and podoplanin and evaluated the renal expression of nephrin, which are indicatives of the status of the glomerular filtration barrier. At the end of the study period, untreated mice showed a significant increase in the glomerular volume per podocyte that was accompanied by focal and segmental loss of glomerular podoplanin protein expression, while MSC administration restored the normal level of podoplanin, nephrin, and the normal glomerular volume per podocyte.

It has been hypothesized that the expansion of the glomerular tuft requires the adaptation of the glomerular epithelial cells to cover a wide area of glomerular capillary wall, a process that requires the reorganization of the actin cytoskeleton and a higher podocyte workload. The increased workload may lead to podocyte damage and eventually podocyte loss [60]. Several studies have reinforced the point that the primary issue of concern is probably not the podocyte number per se but the podocyte number in relation to the territory that each podocyte has to cover designated as glomerular volume per podocyte [61-64]. The glomerular hypertrophy observed in DM mice added to the diabetic microenvironment could result in an increased podocyte workload, followed by the loss of the filtration barrier integrity and the development of albuminuria. By contrast, the preservation of the integrity of the glomerular filtration barrier in the kidney of MSC-treated mice could be associated to the reduction of glomerular hypertrophy and the production of trophic factors. According to this, in vitro studies showed that human adipose-derived MSCs could prevent podocyte injury induced by high glucose mainly through secreting EGF [65]. Additionally, MSCs contribute to podocyte regeneration by trophic factor secretion when administered in an animal model of Alport syndrome [66].

In this study we found that after MSC administration, a small amount of donor cells were present in the kidney, mainly in the tubulointerstitial space. The selectivity of this cell recruitment was supported by the fact that no donor cells were detected when MSCs ${ }^{\text {GFP }}$ were administered into normal mice. Thus, in agreement with already published data, MSC recruitment to kidney depends on the presence of injury [67]. Therapeutics effects with reduced MSCs homing have been reported in other studies of tissue damage [24, 68-71]. So it is likely reasonable to speculate that MSCs protected the diabetic kidney primarily via paracrine mechanisms.

In our study, the improvement of functional parameters was associated with an acceleration of the regeneration phase, as demonstrated by higher amounts of positive Ki-67 nuclei, and increased expression of trophic factors in the kidney of MSC-treated mice. Additionally, this recovery was correlated with an important inhibition of the apoptotic process.

It is well recognized that MSCs can secrete a broad range of trophic factors, such as HGF, bFGF, IGF-1, and EGF, all known to improve the renal function in animal models of kidney injury, due to their antiapoptotic, mitogenic, and morphogenic activities on intrarenal cells $[45,66]$. Based on these observations, we speculate that the mechanisms that mediate protective effects after MSC administration might be primarily related to the paracrine secretion of these factors, creating a proregenerative microenvironment that could induce the endogenous regeneration of the tissue.

In our severe diabetic animal model we showed a systemic increase in the plasmatic levels of bFGF (two weeks after MSC administration) and EGF and HGF (2 and 8 weeks after MSC administration) and also a local increase in the expression levels of these proregenerative factors. Both in vitro and in vivo experiments, EGF can reduce apoptosis and induce the repair of the damage renal tubular epithelial cells [72]. According to this, it has been found in an in vitro study that human adipose-derived MSCs could prevent podocytic apoptosis induced by high glucose mainly through secreting EGF [65] and that MSCs contribute to podocyte regeneration by trophic factor secretion when administered in an animal model of Alport syndrome [66]. Moreover, bFGF can also inhibit the apoptotic process and accelerate renal tissue regeneration when is exogenously administrated [73]. The effect of bFGF on renal injury is particularly important since it has been suggested that bFGF can induce the expression of several tubulogenic/epitheliogenic and angiogenic proteins like Pax-2, bone morphogen protein-7, Noggin, Smad 1-5-8, p-Smad, and hypoxia-inducible factor-1, which in turn are responsible for kidney regeneration [73]. On the other hand, renal damage is exacerbated when bFGF is inhibited [74].

Glucose is the primary fuel source for ROS generation [6] and it is known that oxidative stress condition increase the vulnerability of renal cells [6]. We showed that after MSC transplantation renal cell death and lipid peroxidation were significantly reduced, despite the sustained high blood glucose levels.

There is growing evidence indicating that MSCs can efficiently control oxidative stress. Previously we have demonstrated that the low susceptibility of MSCs to the harmful effect of ROS correlates with the ability of these cells to effectively scavenge peroxide and peroxynitrite due to constitutive 
expression of the enzymes superoxide dismutases 1 and 2, catalase, and glutathione peroxidase [47]. Moreover, MSCs possess the main enzymatic mechanisms to detoxify reactive species, guaranteeing an efficient regulation of oxidative stress [75].

Previous reports of clinical and preclinical studies have indicated that inflammatory cytokines play an important role in the onset and progression of $\mathrm{DN}$ in which macrophages infiltrate the kidney and produce a proinflammatory microenvironment [5]. In this sense, it has been demonstrated that anti-inflammatory treatments and immunotherapy could attenuate podocyte injury, renal fibrosis, and alleviate albuminuria $[14,76]$. Here we showed that the number of infiltrating macrophages in diabetic mice was markedly reduced after MSC administration [13]. Additionally, at molecular level a significant reduction in the plasmatic levels of IL-4, IL-10, and IL-6 was observed in untreated diabetic mice compared with normal animals. These levels were normalized in MSC-treated mice. IL- 4 and IL-10 are the main anti-inflammatory and immunosuppressive cytokines which are produced by several types of immune cells such as regulatory T cells and Th2 lymphocytes [5]. These cytokines play a key role in the regulation of immune responses acting as potent deactivator of the synthesis of monocyte/macrophage proinflammatory cytokine and inhibiting leukocyte infiltration, inflammation, and tissue damage [14]. In different animal models, it has been reported that MSC administration reduces macrophage infiltration into the target tissues [14, 77] and switches macrophages from M1 to M2 phenotype contributing to tissue homeostasis [78]. MSCs can secrete IL4 and IL-10 generating a protective microenvironment that might avoid the immunological destruction of renal cells [9]. Strikingly, plasmatic IL-6 reached normal levels two weeks after MSC administration. This fast recovery may be due in part to the release of IL- 6 by the administered MSCs. IL- 6 is a pleiotropic cytokine that regulates immune responses and inflammatory reactions. Djouad et al. showed that murine MSCs secrete high level of IL-6 and this level is directly correlated to the inhibition of the proliferation of T-cells [79].

In the kidney of MSC-treated mice, we also observed a skewing toward a Th2 profile, as demonstrated by the increased expression of IL- 4 and IL-10. The local attenuation of inflammation has been associated to a reduction in fibrosis and the generation of a protective microenvironment that supports the tissue regeneration $[13,14,77,80]$.

\section{Conclusions}

In summary, our study provides further evidence that MSCs can not only exert antialbuminuric effects but also prevent glomerular capillary occlusion and maintain podocyte density and foot process in the glomerular filtration barrier. In this animal model of severe diabetes mellitus, the improvement of the glomerular function and the morphological recoveries observed after MSC administration could be mediated, at least in part, by the promotion of endogenous regeneration of the kidney tissue due to changes in the local microenvironment and the inhibition of oxidative stress damage and inflammatory reactions skewing a Th2 profile.
We think that the successful treatment of $\mathrm{DN}$ with MSCs demonstrated here holds a substantial promise for the development of novel MSC-based interventions that can prevent the progression of DN. These findings should be confirmed in clinical trial, since MSC transplantations in human patients is feasible and safe.

$\begin{array}{ll}\text { Abbreviations } \\ \text { Alb: } & \text { Albumin } \\ \text { Crea: } & \text { Creatinine } \\ \text { bFGF: } & \text { Basic fibroblast growth factor } \\ \text { BUN: } & \text { Blood urea nitrogen } \\ \text { DAPI: } & 4^{\prime}, 6 \text {-Diamino-2-fenilindol } \\ \text { DM: } & \text { Severe diabetes mellitus } \\ \text { DN: } & \text { Diabetic nephropathy } \\ \text { EGF: } & \text { Epidermal growth factor } \\ \text { GAPDH: } & \text { Glyceraldehyde-3-phosphate dehydrogenase } \\ \text { GBM: } & \text { Glomerular basement membrane } \\ \text { GFP: } & \text { Green fluorescent protein } \\ \text { HGF: } & \text { Hepatocyte growth factor } \\ \text { MSCs: } & \text { Mesenchymal stem cells } \\ \text { Nphs: } & \text { Nephrin } \\ \text { PAS: } & \text { Periodic acid Schiff } \\ \text { PBS: } & \text { Phosphate-buffered saline } \\ \text { ROS: } & \text { Reactive oxygen species } \\ \text { STZ: } & \text { Streptozotocin } \\ \text { TGF- } \beta \text { : } & \text { Transforming growth factor } \beta \\ \text { TUNEL: } & \text { Terminal uridine nucleotide end-labeling } \\ \text { VP: } & \text { Vascular pole } \\ \text { WT-1: } & \text { Wilms' tumor protein } 1 \\ \alpha-S M A: & \text { Smooth muscle actin } \alpha .\end{array}$

\section{Conflict of Interests}

The authors declare that there is no conflict of interests regarding the publication of this paper.

\section{Acknowledgments}

The authors thank Dr. Amelina Albornoz for the English editing of the paper. This work was supported by Grant Fondecyt Regular [1120133] to Marcelo Ezquer.

\section{References}

[1] A. J. Collins, R. N. Foley, C. Herzog et al., "US renal data system 2012 annual data report," The American Journal of Kidney Diseases, vol. 61, no. 1, supplement 1, p. A7, 2013.

[2] Y.-M. Sun, Y. Su, J. Li, and L.-F. Wang, "Recent advances in understanding the biochemical and molecular mechanism of diabetic nephropathy," Biochemical and Biophysical Research Communications, vol. 433, no. 4, pp. 359-361, 2013.

[3] A. K. H. Lim, "Diabetic nephropathy-complications and treatment," International Journal of Nephrology and Renovascular Disease, vol. 7, pp. 361-381, 2014.

[4] K. E. White, "Research into the glomerular podocyte-is it relevant to diabetic nephropathy?" Diabetic Medicine, vol. 23, no. 7, pp. 715-719, 2006. 
[5] A. A. Elmarakby and J. C. Sullivan, "Relationship between oxidative stress and inflammatory cytokines in diabetic nephropathy," Cardiovascular Therapeutics, vol. 30, no. 1, pp. 49-59, 2012.

[6] J. M. Forbes, M. T. Coughlan, and M. E. Cooper, "Oxidative stress as a major culprit in kidney disease in diabetes," Diabetes, vol. 57, no. 6, pp. 1446-1454, 2008.

[7] S.-I. Yamagishi, S. Maeda, T. Matsui, S. Ueda, K. Fukami, and S. Okuda, "Role of advanced glycation end products (AGEs) and oxidative stress in vascular complications in diabetes," Biochimica et Biophysica Acta, vol. 1820, no. 5, pp. 663-671, 2012.

[8] F. N. Ziyadeh, "Mediators of diabetic renal disease: the case for TGF- $\beta$ as the major mediator," Journal of the American Society of Nephrology, vol. 15, supplement 1, pp. S55-S57, 2004.

[9] F. Tögel and C. Westenfelder, "Adult bone marrow-derived stem cells for organ regeneration and repair," Developmental Dynamics, vol. 236, no. 12, pp. 3321-3331, 2007.

[10] A. I. Caplan, "The mesengenic process," Clinics in Plastic Surgery, vol. 21, no. 3, pp. 429-435, 1994.

[11] F. Anglani, M. Forino, D. del Prete, E. Tosetto, R. Torregrossa, and A. D’Angelo, "In search of adult renal stem cells," Journal of Cellular and Molecular Medicine, vol. 8, no. 4, pp. 474-487, 2004.

[12] S. Sedrakyan, S. Angelow, R. E. de Filippo, and L. Perin, "Stem cells as a therapeutic approach to chronic kidney diseases," Current Urology Reports, vol. 13, no. 1, pp. 47-54, 2012.

[13] P. Semedo, C. G. Palasio, C. D. Oliveira et al., "Early modulation of inflammation by mesenchymal stem cell after acute kidney injury," International Immunopharmacology, vol. 9, no. 6, pp. 677-682, 2009.

[14] P. Semedo, M. Correa-Costa, M. A. Cenedeze et al., "Mesenchymal stem cells attenuate renal fibrosis through immune modulation and remodeling properties in a rat remnant kidney model," Stem Cells, vol. 27, no. 12, pp. 3063-3073, 2009.

[15] G. C. Davey, S. B. Patil, A. O’Loughlin, and T. O'Brien, "Mesenchymal stem cell-based treatment for microvascular and secondary complications of diabetes mellitus," Frontiers in Endocrinology, vol. 5, article 86, 2014.

[16] F. E. Ezquer, M. E. Ezquer, D. B. Parrau, D. Carpio, A. J. Yañez, and P. A. Conget, "Systemic administration of multipotent mesenchymal stromal cells reverts hyperglycemia and prevents nephropathy in type 1 diabetic mice," Biology of Blood and Marrow Transplantation, vol. 14, no. 6, pp. 631-640, 2008.

[17] R. H. Lee, M. J. Seo, R. L. Reger et al., "Multipotent stromal cells from human marrow home to and promote repair of pancreatic islets and renal glomeruli in diabetic NOD/scid mice," Proceedings of the National Academy of Sciences of the United States of America, vol. 103, no. 46, pp. 17438-17443, 2006.

[18] S. Lv, J. Cheng, A. Sun et al., "Mesenchymal stem cells transplantation ameliorates glomerular injury in streptozotocin-induced diabetic nephropathy in rats via inhibiting oxidative stress," Diabetes Research and Clinical Practice, vol. 104, no. 1, pp. 143154, 2014.

[19] J. Ouyang, G. Hu, Y. Wen, and X. Zhang, "Preventive effects of syngeneic bone marrow transplantation on diabetic nephropathy in mice," Transplant Immunology, vol. 22, no. 3-4, pp. 184190, 2010.

[20] H. Zhou, H.-M. Tian, Y. Long et al., "Mesenchymal stem cells transplantation mildly ameliorates experimental diabetic nephropathy in rats," Chinese Medical Journal, vol. 122, no. 21, pp. 2573-2579, 2009.
[21] F. Ezquer, M. Ezquer, V. Simon et al., "Endovenous administration of bone-marrow-derived multipotent mesenchymal stromal cells prevents renal failure in diabetic mice," Biology of Blood and Marrow Transplantation, vol. 15, no. 11, pp. 1354-1365, 2009.

[22] M. Katoh, Y. Ohmachi, Y. Kurosawa, H. Yoneda, N. Tanaka, and H. Narita, "Effects of imidapril and captopril on streptozotocininduced diabetic nephropathy in mice," European Journal of Pharmacology, vol. 398, no. 3, pp. 381-387, 2000.

[23] Y.-C. Tay, Y. Wang, L. Kairaitis, G. K. Rangan, C. Zhang, and D. C. H. Harris, "Can murine diabetic nephropathy be separated from superimposed acute renal failure?" Kidney International, vol. 68, no. 1, pp. 391-398, 2005.

[24] F. Ezquer, M. Ezquer, D. Contador, M. Ricca, V. Simon, and P. Conget, "The antidiabetic effect of mesenchymal stem cells is unrelated to their transdifferentiation potential but to their capability to restore Th1/Th2 balance and to modify the pancreatic microenvironment," Stem Cells, vol. 30, no. 8, pp. 1664-1674, 2012.

[25] M. Ezquer, F. Ezquer, M. Ricca, C. Allers, and P. Conget, "Intravenous administration of multipotent stromal cells prevents the onset of non-alcoholic steatohepatitis in obese mice with metabolic syndrome," Journal of Hepatology, vol. 55, no. 5, pp. 1112-1120, 2011.

[26] B. D. Kubiak, S. P. Albert, L. A. Gatto et al., "Peritoneal negative pressure therapy prevents multiple organ injury in a chronic porcine sepsis and ischemia/reperfusion model," Shock, vol. 34, no. 5, pp. 525-534, 2010.

[27] J. Ma, H. Nishimura, A. Fogo, V. Kon, T. Inagami, and I. Ichikawa, "Accelerated fibrosis and collagen deposition develop in the renal interstitium of angiotensin type 2 receptor null mutant mice during ureteral obstruction," Kidney International, vol. 53, no. 4, pp. 937-944, 1998.

[28] D. Sheehan and B. Hrapchak, Theory and Practice of Histotechnology, Battelle Press, Columbus, Ohio, USA, 1980.

[29] A. Benigni, C. Zoja, C. Zatelli et al., "Vasopeptidase inhibitor restores the balance of vasoactive hormones in progressive nephropathy," Kidney International, vol. 66, no. 5, pp. 1959-1965, 2004.

[30] G. H. Tesch, "Macrophages and diabetic nephropathy," Seminars in Nephrology, vol. 30, no. 3, pp. 290-301, 2010.

[31] C. E. Alpers, K. L. Hudkins, A. M. Gown, and R. J. Johnson, "Enhanced expression of 'muscle-specific' actin in glomerulonephritis," Kidney International, vol. 41, no. 5, pp. 1134-1142, 1992.

[32] Y. Utsunomiya, T. Kawamura, A. Abe et al., "Significance of mesangial expression of $\alpha$-smooth muscle actin in the progression of IgA nephropathy," American Journal of Kidney Diseases, vol. 34, no. 5, pp. 902-910, 1999.

[33] T. J. M. Geleilete, R. S. Costa, M. Dantas, and T. M. Coimbra, "Alpha-smooth muscle actin and proliferating cell nuclear antigen expression in focal segmental glomerulosclerosis: functional and structural parameters of renal disease progression," Brazilian Journal of Medical and Biological Research, vol. 34, no. 8, pp. 985-991, 2001.

[34] D. H. T. Ijpelaar, A. Schulz, K. Koop et al., "Glomerular hypertrophy precedes albuminuria and segmental loss of podoplanin in podocytes in Munich-Wistar-Frömter rats," The American Journal of Physiology-Renal Physiology, vol. 294, no. 4, pp. F758-F767, 2008.

[35] M. Notoya, T. Shinosaki, T. Kobayashi, T. Sakai, and H. Kurihara, "Intussusceptive capillary growth is required for 
glomerular repair in rat Thy-1.1 nephritis," Kidney International, vol. 63, no. 4, pp. 1365-1373, 2003.

[36] A. Salahudeen, V. Poovala, W. Parry et al., "Cisplatin induces $\mathrm{N}$-acetyl cysteine suppressible F2 isoprostane production and injury in renal tubular epithehal cells," Journal of the American Society of Nephrology, vol. 9, no. 8, pp. 1448-1455, 1998.

[37] D. A. Butterfield and C. M. Lauderback, "Lipid peroxidation and protein oxidation in Alzheimer's disease brain: potential causes and consequences involving amyloid $\beta$-peptide-associated free radical oxidative stress," Free Radical Biology and Medicine, vol. 32, no. 11, pp. 1050-1060, 2002.

[38] H. Zhou, A. Kato, T. Miyaji et al., "Urinary marker for oxidative stress in kidneys in cisplatin-induced acute renal failure in rats," Nephrology Dialysis Transplantation, vol. 21, no. 3, pp. 616-623, 2006.

[39] R. Mahfouz, R. Sharma, D. Sharma, E. Sabanegh, and A. Agarwal, "Diagnostic value of the total antioxidant capacity (TAC) in human seminal plasma," Fertility and Sterility, vol. 91, no. 3, pp. 805-811, 2009.

[40] T. Shimo, M. Ohshita, J. Katayama et al., "Significance of intraglomerular expression of $\alpha$-smooth muscle actin, desmin, and PDGF receptor on glomerulosclerosis in the rat remnant kidney model," Journal of Toxicologic Pathology, vol. 11, no. 4, pp. 229-234, 1998.

[41] J. Floege, M. W. Burns, C. E. Alpers et al., "Glomerular cell proliferation and PDGF expression precede glomerulosclerosis in the remnant kidney model," Kidney International, vol. 41, no. 2, pp. 297-309, 1992.

[42] Y. Kaneko, K. Nakazawa, M. Higuchi, K. Hora, and H. Shigematsu, "Glomerular expression of $\alpha$-smooth muscle actin reflects disease activity of IgA nephropathy," Pathology International, vol. 51, no. 11, pp. 833-844, 2001.

[43] G. I. Welsh and M. A. Saleem, "Nephrin-signature molecule of the glomerular podocyte?" Journal of Pathology, vol. 220, no. 3, pp. 328-337, 2010.

[44] H. Yuan, E. Takeuchi, and D. J. Salant, "Podocyte slit-diaphragm protein nephrin is linked to the actin cytoskeleton," The American Journal of Physiology: Renal Physiology, vol. 282, no. 4, pp. F585-F591, 2002.

[45] F. Tögel, K. Weiss, Y. Yang, Z. Hu, P. Zhang, and C. Westenfelder, "Vasculotropic, paracrine actions of infused mesenchymal stem cells are important to the recovery from acute kidney injury," The American Journal of Physiology - Renal Physiology, vol. 292, no. 5, pp. F1626-F1635, 2007.

[46] M. H. Little, "Regrow or repair: potential regenerative therapies for the kidney," Journal of the American Society of Nephrology, vol. 17, no. 9, pp. 2390-2401, 2006.

[47] A. Valle-Prieto and P. A. Conget, "Human mesenchymal stem cells efficiently manage oxidative stress," Stem Cells and Development, vol. 19, no. 12, pp. 1885-1893, 2010.

[48] J. F. Navarro-González and C. Mora-Fernández, "The role of inflammatory cytokines in diabetic nephropathy," Journal of the American Society of Nephrology, vol. 19, no. 3, pp. 433-442, 2008.

[49] D. Nguyen, F. Ping, W. Mu, P. Hill, R. C. Atkins, and S. J. Chadban, "Macrophage accumulation in human progressive diabetic nephropathy," Nephrology, vol. 11, no. 3, pp. 226-231, 2006.

[50] F. Y. Chow, D. J. Nikolic-Paterson, R. C. Atkins, and G. H. Tesch, "Macrophages in streptozotocin-induced diabetic nephropathy: potential role in renal fibrosis," Nephrology Dialysis Transplantation, vol. 19, no. 12, pp. 2987-2996, 2004.
[51] F. Y. Chow, D. J. Nikolic-Paterson, E. Ozols, R. C. Atkins, B. J. Rollin, and G. H. Tesch, "Monocyte chemoattractant protein-1 promotes the development of diabetic renal injury in streptozotocin-treated mice," Kidney International, vol. 69, no. 1, pp. 73-80, 2006.

[52] H. Akahori, T. Ota, M. Torita, H. Ando, S. Kaneko, and T. Takamura, "Tranilast prevents the progression of experimental diabetic nephropathy through suppression of enhanced extracellular matrix gene expression," Journal of Pharmacology and Experimental Therapeutics, vol. 314, no. 2, pp. 514-521, 2005.

[53] S. Lv, G. Liu, A. Sun et al., "Mesenchymal stem cells ameliorate diabetic glomerular fibrosis in vivo and in vitro by inhibiting TGF- $\beta$ signalling via secretion of bone morphogenetic protein 7," Diabetes and Vascular Disease Research, vol. 11, no. 4, pp. 251261, 2014.

[54] M. Danilewicz and M. Wagrowska-Danilewicz, "Morphometric and immunohistochemical insight into focal segmental glomerulosclerosis in obese and non-obese patients," Nefrologia, vol. 29, no. 1, pp. 35-41, 2009.

[55] H. Kawachi, N. Miyauchi, K. Suzuki, D. H. Gi, M. Orikasa, and F. Shimizu, "Role of podocyte slit diaphragm as a filtration barrier," Nephrology, vol. 11, no. 4, pp. 274-281, 2006.

[56] F. N. Ziyadeh and G. Wolf, "Pathogenesis of the podocytopathy and proteinuria in diabetic glomerulopathy," Current Diabetes Reviews, vol. 4, no. 1, pp. 39-45, 2008.

[57] K. Koop, M. Eikmans, M. Wehland et al., "Selective loss of podoplanin protein expression accompanies proteinuria and precedes alterations in podocyte morphology in a spontaneous proteinuric rat model," The American Journal of Pathology, vol. 173, no. 2, pp. 315-326, 2008.

[58] R. G. Langham, D. J. Kelly, A. J. Cox et al., "Proteinuria and the expression of the podocyte slit diaphragm protein, nephrin, in diabetic nephropathy: effects of angiotensin converting enzyme inhibition," Diabetologia, vol. 45, no. 11, pp. 1572-1576, 2002.

[59] P. Mundel and J. Reiser, "Proteinuria: an enzymatic disease of the podocyte," Kidney International, vol. 77, no. 7, pp. 571-580, 2010.

[60] J. E. Wiggins, M. Goyal, S. K. Sanden et al., "Podocyte hypertrophy, 'adaptation' and 'decompensation' associated with glomerular enlargement and glomerulosclerosis in the aging rat: prevention by calorie restriction," Journal of the American Society of Nephrology, vol. 16, no. 10, pp. 2953-2966, 2005.

[61] D. B. Bhathena, "Glomerular basement membrane length to podocyte ratio in human nephronopenia: implications for focal segmental glomerulosclerosis," American Journal of Kidney Diseases, vol. 41, no. 6, pp. 1179-1188, 2003.

[62] A. B. Fogo, "Glomerular hypertension, abnormal glomerular growth, and progression of renal diseases," Kidney International. Supplement, vol. 57, no. 75, pp. S15-S21, 2000.

[63] Y. H. Kim, M. Goyal, D. Kurnit et al., "Podocyte depletion and glomerulosclerosis have a direct relationship in the PANtreated rat," Kidney International, vol. 60, no. 3, pp. 957-968, 2001.

[64] M. E. Pagtalunan, P. L. Miller, S. Jumping-Eagle et al., "Podocyte loss and progressive glomerular injury in type II diabetes," The Journal of Clinical Investigation, vol. 99, no. 2, pp. 342-348, 1997.

[65] D. Li, N. Wang, L. Zhang et al., "Mesenchymal stem cells protect podocytes from apoptosis induced by high glucose via secretion of epithelial growth factor," Stem Cell Research and Therapy, vol. 4, no. 5, article 103, 2013. 
[66] E. I. Prodromidi, R. Poulsom, R. Jeffery et al., "Bone marrowderived cells contribute to podocyte regeneration and amelioration of renal disease in a mouse model of Alport syndrome," Stem Cells, vol. 24, no. 11, pp. 2448-2455, 2006.

[67] Y. Zhang, C. Ye, G. Wang et al., "Kidney-targeted transplantation of mesenchymal stem cells by ultrasound-targeted microbubble destruction promotes kidney repair in diabetic nephropathy rats," BioMed Research International, vol. 2013, Article ID 526367, 13 pages, 2013.

[68] E. B. Oliveira-Sales, E. Maquigussa, P. Semedo et al., "Mesenchymal stem cells (MSC) prevented the progression of renovascular hypertension, improved renal function and architecture," PLoS ONE, vol. 8, no. 11, Article ID e78464, 2013.

[69] A. I. Caplan and J. E. Dennis, "Mesenchymal stem cells as trophic mediators," Journal of Cellular Biochemistry, vol. 98, no. 5, pp. 1076-1084, 2006.

[70] D. J. Prockop, D. J. Kota, N. Bazhanov, and R. L. Reger, "Evolving paradigms for repair of tissues by adult stem/progenitor cells (MSCs)," Journal of Cellular and Molecular Medicine, vol. 14, no. 9, pp. 2190-2199, 2010.

[71] Y. Wang, H. E. Johnsen, S. Mortensen et al., "Changes in circulating mesenchymal stem cells, stem cell homing factor, and vascular growth factors in patients with acute ST elevation myocardial infarction treated with primary percutaneous coronary intervention," Heart, vol. 92, no. 6, pp. 768-774, 2006.

[72] C. Lu, W. Ren, X.-M. Su, J.-Q. Chen, S.-H. Wu, and G.-P. Zhou, "EGF-recruited JunD/c-fos complexes activate CD2AP gene promoter and suppress apoptosis in renal tubular epithelial cells," Gene, vol. 433, no. 1-2, pp. 56-64, 2009.

[73] S. Villanueva, C. Cespedes, A. Gonzalez, and C. P. Vio, "bFGF induces an earlier expression of nephrogenic proteins after ischemic acute renal failure," The American Journal of Physiology-Regulatory Integrative and Comparative Physiology, vol. 291, no. 6, pp. R1677-R1687, 2006.

[74] S. Villanueva, C. Cespedes, A. A. Gonzalez, E. Roessler, and C. P. Vio, "Inhibition of bFGF-receptor type 2 increases kidney damage and suppresses nephrogenic protein expression after ischemic acute renal failure," American Journal of PhysiologyRegulatory Integrative and Comparative Physiology, vol. 294, no. 3, pp. R819-R828, 2008.

[75] W. A. Silva Jr., D. T. Covas, R. A. Panepucci et al., "The profile of gene expression of human marrow mesenchymal stem cells," Stem Cells, vol. 21, no. 6, pp. 661-669, 2003.

[76] Y. Zhang, B. Chen, X.-H. Hou et al., "Effects of mycophenolate mofetil, valsartan and their combined therapy on preventing podocyte loss in early stage of diabetic nephropathy in rats," Chinese Medical Journal, vol. 120, no. 11, pp. 988-995, 2007.

[77] S. Villanueva, E. Ewertz, F. Carrión et al., "Mesenchymal stem cell injection ameliorates chronic renal failure in a rat model," Clinical Science, vol. 121, no. 11, pp. 489-499, 2011.

[78] W. Li, Q. Zhang, M. Wang et al., "Macrophages are involved in the protective role of human umbilical cord-derived stromal cells in renal ischemia-reperfusion injury," Stem Cell Research, vol. 10, no. 3, pp. 405-416, 2013.

[79] F. Djouad, L.-M. Charbonnier, C. Bouffi et al., "Mesenchymal stem cells inhibit the differentiation of dendritic cells through an interleukin-6-dependent mechanism," Stem Cells, vol. 25, no. 8, pp. 2025-2032, 2007.

[80] M. E. Ezquer, F. E. Ezquer, M. L. Arango-Rodríguez, and P. A. Conget, "MSC transplantation: a promising therapeutic strategy to manage the onset and progression of diabetic nephropathy," Biological Research, vol. 45, no. 3, pp. 289-296, 2012. 


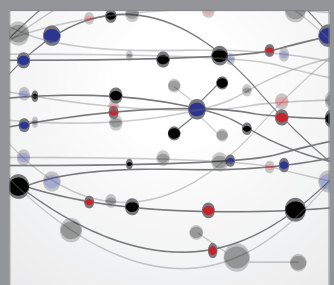

The Scientific World Journal
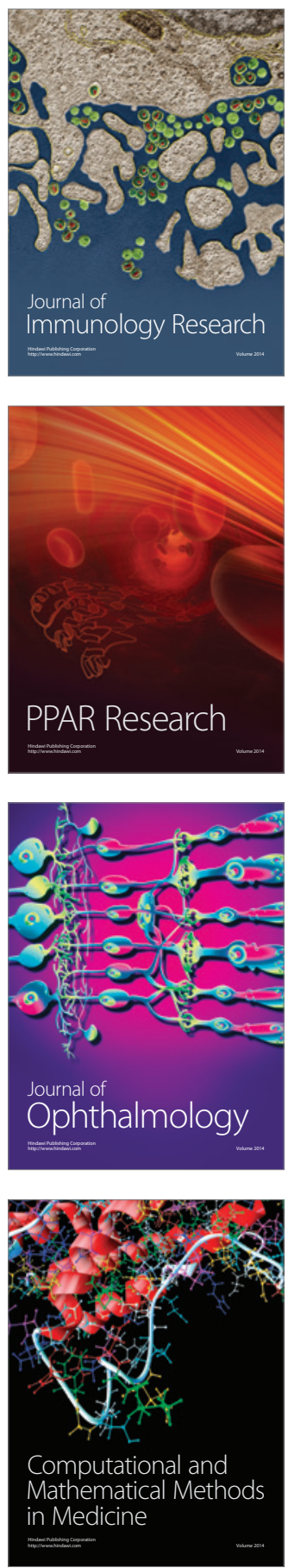

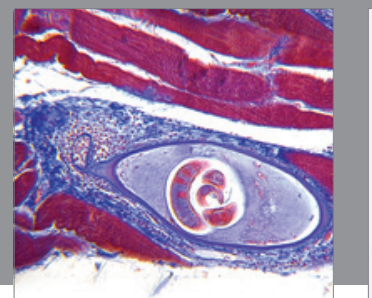

Gastroenterology

Research and Practice
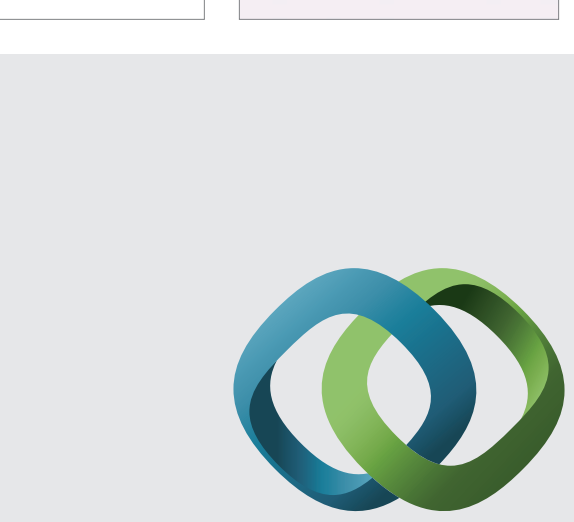

\section{Hindawi}

Submit your manuscripts at

http://www.hindawi.com
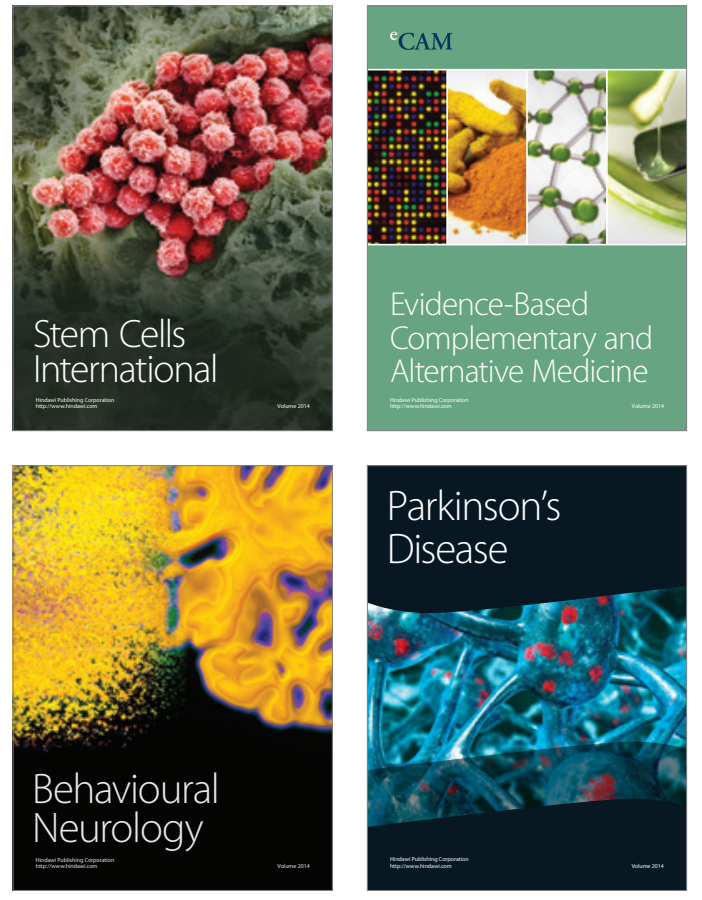
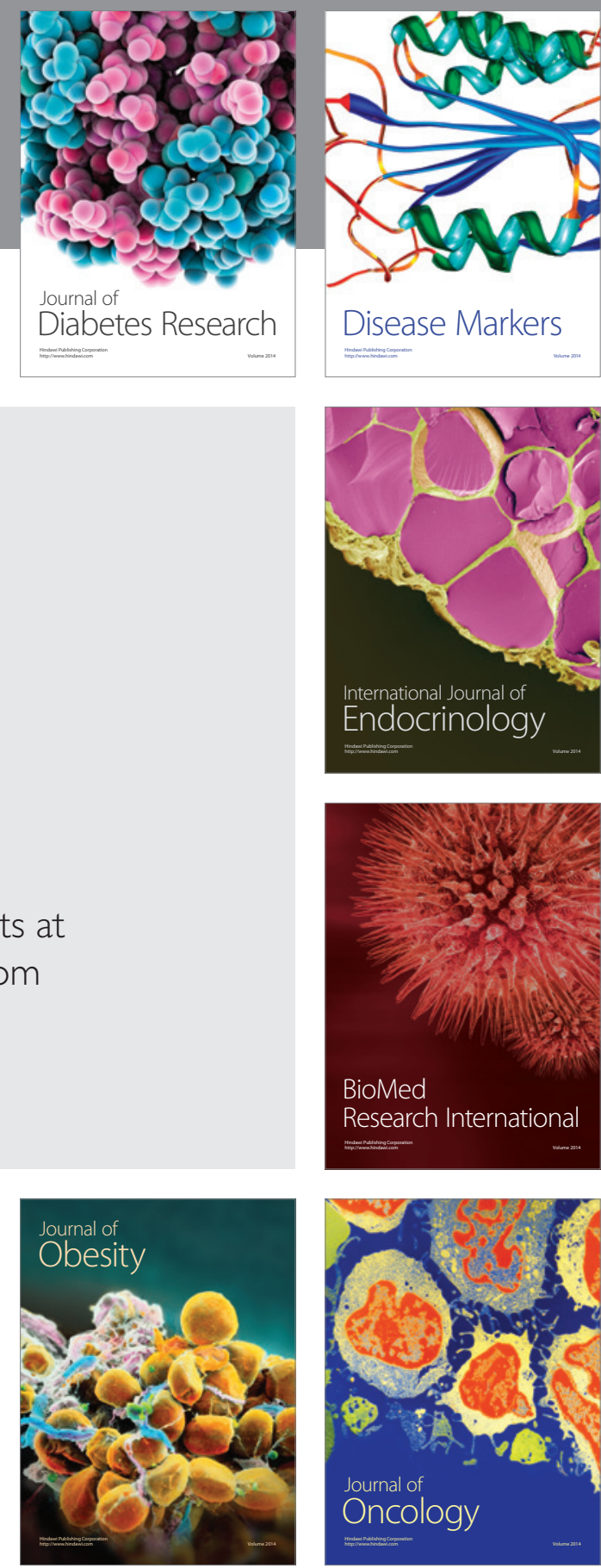

Disease Markers
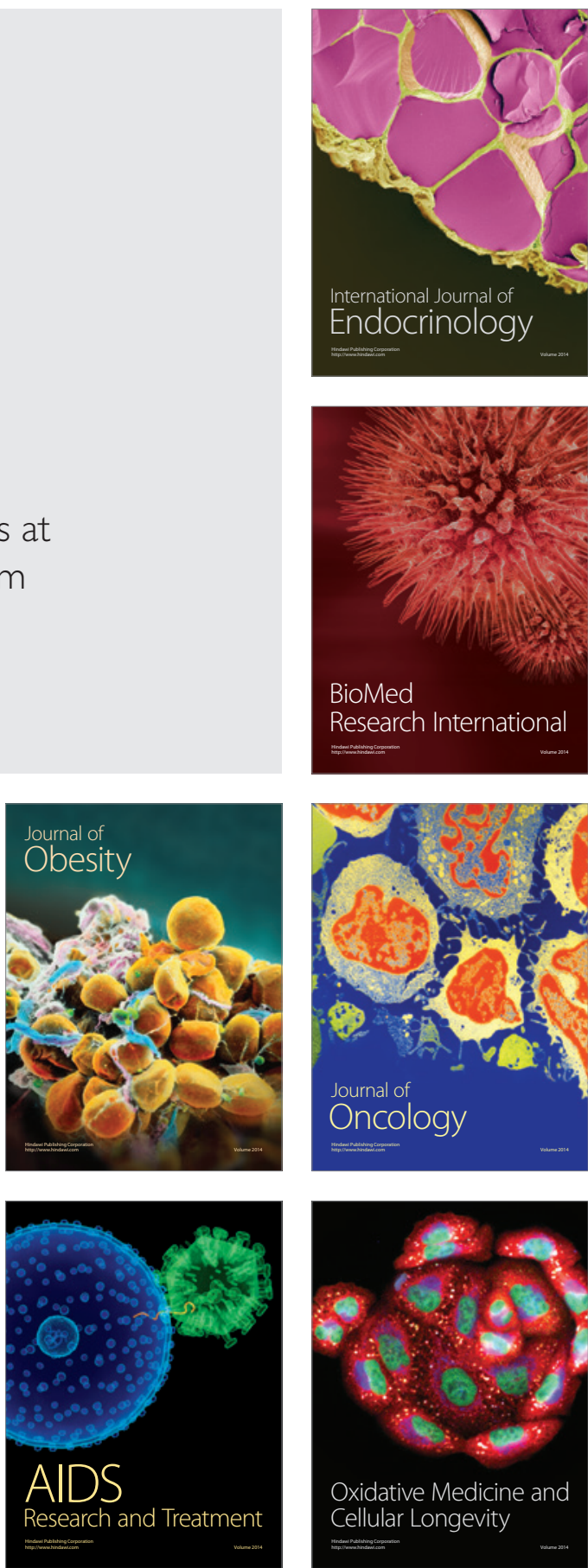